\title{
EL SEÑORÍO, UNA RAZÓN DE SER DE LOS ADELANTAMIENTOS MODERNOS
}

por

\section{PILAR ARREGUI ZAMORANO}

Universidad de Salamanca.

RESUMEN: En el umbral del siglo XVI los Reyes Católicos reflotaron dos de los adelantamientos bajomedievales -el de Castilla y el de León-con el objetivo prio. ritario de patrullar en aguas señoriales. La realidad señorial que siempre babia acompañado a los adelantamientos cobró, a partir de entonces, un especial protagonismo a los ojos de estos monarcas y a los de sus sucesores en el trono. Todos ellos, viendo crecer el "peso" del señorio, se sintieron urgidos a potenciar las alcaldias de adelantamiento diseñadas, en buena medida, como "contrapeso»

El objeto de estas líneas no es tanto estudiar el "contrapeso», como constatar el "peso" que lo exigió, dejando constancia de la abultada presencia del señorio en uno de los tres adelantamientos modernos: el de Castilla-Burgos, $y$ en un momento histórico muy concreto: el ocaso del reinado de Felipe II que consideraba a los alcaldes mayores de adelantamiento como un "freno" para los señores.

P'ALABRAS CLAVE: Señorio. Adelantamientos modernos. Adelantamiento de Burgos.

ABSTRACT: On the thresbold of the sixteenth century the Catbolic Monarchs relaunched two of the late medieval adelantamientos — that of Castile and that of Leon-with the main objective of patrolling seignorial waters. From then on, the seignorial reality that bad always accompanied the adelantamientos became specially important in the eyes of the monarchs and of their succesors on the throne. All of them, seeing the "weightw of the nobility grow, felt the need to empower the office of alcalde mayor, which beaded the adelantamientos, largely designed as a "counterweight》.

The object of this paper is not so much to study the "counteryeight" as to demonstrate the «weight» that demanded it, giving evidence of the massive presence of the nobility in one of the three modern adelantamientos: that of Burgos, and at a very specific bistorical moment: the waning of the reign of Philip II who considered the alcaldes mayores of the adelantamientos as a brake on the power of the nobility.

KEY wORDS: Seigniory. Modern Adelantamientos. Adelantamiento of Burgos.

Hipksta, LIX/2, nüm. 202 (1999) 493-531 
Tiempo atrás dejaba apuntada la relación que creía encontrar entre la condición señorial de muchas de las ticrras de la Meseta Norte y la persistencia, si bien harto reformada, de los adelantamientos como distritos jurisdiccionales más allá de su etapa bajomedieval ${ }^{1}$. Aquella relación, entonces vislumbrada, hoy me parece una realidad incuestionable. En el mismo umbral del siglo XVI los Reyes Católicos reflotaron dos de los adelantamientos bajomedievales -el de Castilla y el de León- con el objetivo prioritario de patrullar en aguas señoriales ${ }^{2}$. Así, la realidad señorial, que siempre había acompañado a los adelantamientos, cobró entonces un especial protagonismo a los ojos de estos monarcas que, sabiéndose herederos de una etapa de gran expansión señorial, se sintiezon urgidos a contrapesar ${ }^{3}$.

El objeto de estas líneas no es tanto estudiar el «contrapeso», diseñado por tan ilustres monarcas, como constatar el "peso", es decir, la realidad señorial que exigió la presencia de aquél.

Una vez en el trono, los Reyes Católicos trataron de conjugar dos políticas: la una, encaminada a simplificar y fortalecer la maquinaria administrativa; la otra, dirigida a establecer los límites del poder teal frente a una nobleza que, al igual que la Corona, salió fortalecida de la contienda 4 .

Mediante las medidas adoptadas en las Cortes de Madrigal y, especialmente, en las recogidas en el ordenamiento de las Cortes de Toledo de 1480, Isabel y Fernando dejaron trazadas las líneas maestras de esa obra que se sentían urgidos a levantar. Así, justo en el momento de tránsito hacia la nueva centuria, nuestros «ínclitos reyes», que llevaban muy adelantada su obra de «reformación", percibieton en su arquitectura una importante laguna que era necesario colmar. A pesar del despliegue de los corregimientos, en los extensos territo-

1 «El alcalde mayor del adelantamiento de Castilla en el momento de la conquista del Nuevo Mundo" en IX Congreso del Instituto Internacional de Historia del Derecho Indiano. Actas y Estudios. Madrid, 1991, t. 1, págs. 383-403.

2 «...agora por algunas causas e razones que a ello nos mueven cumplideras a nuestro servicio e execucion de la nuestra justicia e pas e sosyego de las villas e lugares del dicho adelantamiento, asi realengas, como abadengas e señotios e hordenes e behetrias, nuestra merced e voluntad es de proveer del dicho oficio de alcaldia...) (Archivo Municipal de Burgos (AMB)Sección Histórica (HI), $\mathrm{n}^{\circ}$ 4051). Son palabras que pertenecen al nombramiento de Juan Arias de Villasinda como primer alcalde mayor del adelantamiento de Castilla tras la suspensión de las alcaldias de adelantamiento impuesta en las Cortes de Toledo de 1480. Sobre su contenido, véase el trabajo citado en la nota anterior.

3 De «fabulosa marea señorial» calificó, hace ya muchos años, S. DE MOxó lo ocurrido en el siglo anterior al advenimiento de los Monarcas Católicos. Y de "política de contracción» su actitud hacia ella, ( $(\mathrm{El}$ señorio legado medieval» en Cuadernos de Historia, 1, 1967, págs. 110-111).

4 Sú̉rez Fernández en La España de los Reyes Católicos (1474-1516)m, t. XVII de la Historia de España Menendez Pidal, Madrid, 1969 y Clavero en ElMajorazogopropiedad faudalen Castilla (1369-1836), Madrid, 1974, partiendo desde puntos de vista diferentes y utilizando metodologías distintas, legan, sin embargo, a la misma conclusión respecto a la salida victotiosa de las dos partes contendientes (vid. S. DE Dios, E/ Consejo Real de Castilla (1385-1522), Madrid, 1982, págs. 141-146).

Mipania, LIX/2, núm. 202 (1999) 493-531 
rios meseteños aun quedaba demasiado espacio por controlat. Un espacio que no era propicio para los corregidores, concebidos para ejercer su actividad en el ámbito municipal, porque se trataba de un territotio integrado por extensas zonas rurales donde no existían casi concejos importantes. Eran, en buena medida, lugares de señorío en los que, si cabía, se hacía aun más urgente garantizar el orden y la adecuada administración de justicia ${ }^{5}$; donde eta muy necesario «remediar con tiempo las cosas que hubiere menester remedio» 6 .

La vatiada cualidad de esas tierras — - realengas, abadengas e señorio e hordenes e behetrias-, que no son corregimiento de realengo, y los múltiples intereses que en ellas se movían, llevará a los monarcas a ponerlas bajo la autoridad y jurisdicción del alcalde mayor de adelantamiento. Si el corregidor, como delegado del monarca en el municipios, servía a la política de acrecentamiento del poder real y al control de los municipios, el alcalde mayor haría lo propio en los adelantamientos, tierras principalmente --aunque no exclusivamente- señoriales. Se plasmaba así el deseo monárquico de controlar a la nobleza, abriéndose una importante vía para la intervención del rey en el señorío. Los Grandes, que acusaron la maniobra regia, no dudaron en movilizarse para neutralizarla, aprovechando para ello todas las oportunidades que se les presentaron ${ }^{7}$.

El tema no es baladí. Hablar del alcalde mayor del adelantamiento es hablar de una fórmula para la organización del territorio; de un instrumento de control del régimen señorial en manos de la monarquía. Es, concretamente y siguiendo el símil utilizado por González Alonso, reflexionar sobre uno de esos upuentes que engarzaban el poder del Estado con la autoridad ostentada por los señores y delimitaban el disfrute de las prerrogativas inherentes a sus respectivos ámbitos» ${ }^{8}$, porque el alcalde mayor de adelantamiento fue un delegado regio en territorios principalmente señoriales con la misión de hacer efectivo el sometimiento del poder señorial al superior poder del monarca. Un sometimiento que, como espero poder demostrar en un breve plazo, se hizo efectivo sin necesidad de tener que acudir a expedientes tales como: los "casos

5 Los autores han llamado la atención sobre el carácter marcadamente rural del régimen señorial, poderoso obstáculo para el control por parte de la Corona (GuILARTE, E/ régimen señorial en el siglo XVT, Valladolid, 1987, págs. 207 y sigs; $\mathrm{y}$ N. SALOMÓN, La vida rural en tiempos de Felipe II, Barcelona, 1982, págs. 196 y sigs.).

6 QQue clara tiene el monarca en su cabeza esta realidad!: ... los nuestros subditos son muchos e repartidos en muchas tierras e provincias de diversas qualidades y condiciones...) (Cortes de Toledo de 1480 , ley 60 , en CLC, IV, pág. 137 ).

7 A la muerte de la reina Isabel y con el fin de poder ser considerado como legítimo sucesor, se le aconseja a Fernando que temple algunas de las decisiones tomadas por considerarlas excesivamente duras de cumplir. Entre otras, se le pide que suprima «das alcaldyas del adelantado que se introduxeron nuevamente: de que se quexaban especialmente los Grandes...) (J. Z $\mathrm{U}$ RTTA, Historia del Rey don Hernando e/ Catholico de las empresas, y ligas de Italia. Compuesta por... Cbonista del Reyno de Aragón, Zaragoza, 1580, t. I, fols. 341 y sigs.).

8 «Notas sobre las relaciones del Estado con la administración señorial en la Castilla modernan, en $\mathrm{AHDE}, 53,1983$, pág. 381.

Hippunia, LIX/2, núm. 202 (1999) 493-531 
de corte», la "mengua» de justicia o la apelación ante los tribunales superiores del rey. En los señoríos enclavados en territorio de adelantamiento la (mayoria) de justicia ", la "suprema jurisdicción» que corresponde exclusivamente al monarca, se hizo efectiva de modo ordinario a través de la capacidad que se otorgó a estos alcaldes para, entre otras cosas, poder conocer todas las causas civiles y criminales que ante ellos se presentaran, tạnto en primera instancia - con ciertas restricciones en materia civil- como en grado de apelación, independientemente de que se tratara de un pleito entre vasallos o entre señores y vasallos.

Pero fiel a mi declaración de intenciones, no utilizaré estas páginas para desentrañar el "contrapeso»: los alcaldes mayores de adelantamiento y sus audiencias, sus atribuciones y su modo de operar ${ }^{10}$. En esta ocasión deseo detenerme ante el (peso", contemplando y valorando la presencia del señorio en el marco de los adelantamientos modernos. El objetivo es pues muy simple: dejar constancia de la abultada presencia del señorio en los distritos de adelantamiento. Tan abultada que, en mi opinión y de ahí el título que encabeza las presentes páginas, es ésta y no otra la principal razón que impulsó a los Reyes Católicos a poner de nuevo en marcha las alcaldías mayores de adelantamiento; tan abundante, que fue éste y no otro el argumento más poderoso para mantener su andadura en los siglos modernos. Felipe II se teferirá a ellos considerándolos como su «freno de los señores»" ". Traigo a colación a este monarca y a su franca manera de concebirlos, porque es en concreto la situación existente el año en que se cierra su reinado la que deseo presentar aquí.

En el ocaso de su reinado, Felipe II, consciente del importante proceso de señorialización que se había producido en el ámbito rural castellano a lo largo del siglo XVI, del que sin duda se considera cómplice, se preocupó por poner a punto las alcaldías mayores de adelantamiento. El upeso» que ha crecido obliga a consolidar el «contrapeso». Para dicha puesta a punto, nada mejor que poner en marcha una visita a los adelantamientos ${ }^{12}$. Era la visita una institución que, a mediados del siglo XVI, además de ser un procedimiento para la exigencia de responsabilidad a los oficiales visitados, se había revelado como un formidable vehículo para conocer, controlat y reformar la institución visitada ${ }^{13}$ y a ello se dirige ésta de los adelantamientos.

9 Véase J. L. BERMỆ, «Mayoria de justicia del rey y jurisdicciones señoriales en la Baja Edad Media castellanay, en Actas de las I Jornadas de Metodología aplicada a las Ciencias Históricas. II Historia Medieval, Santiago de Compostela, 1975, págs. 207-215.

10 Extremos, todos ellos, contemplados en una monografia que acabo de concluir, Los adelantamientos de Castilla, León y Campos en la Edad Moderna (1474-1643), (en prensa).

11 Archivo General de Simancas (AGS) - Cámara de Castilla (CC), 1083, 56.

12 No era la primera que se hacía, tampoco la única. En los primetos años de la década de los cuarenta del siglo que ahora acaba, el Dr. Mora habia realizado la primera por orden del Emperador. Fruto de ella se dieron las Ordenanzas de 1543, recogidas en la Nueva Recopilación y que supusieron la primera reglamentación para los adelantamientos. La siguiente la llevó a cabo, en 1559, el lic. Juan de Vargas; de ella no se siguió ordenanza alguna.

${ }_{13}$ Tras un profundo y profuso estudio sobre la génesis histórica de las visitas a las Chancillerías castellanas, C. Garrign temina diciendo que "a mediados del siglo XVI la visita se había

Hippania, $1 . .1 X / 2$, núm. $202(1999) 493-531$ 
De esta manera, a finales de 1596 , se nombra como visitador de los adelantamientos de León, Burgos y Campos al Coronel Luján ${ }^{14}$. En plena ejecución de su cometido, cuando se halla realizando la visita al adelantamiento de Burgos (estamos en el mes de abril de 1598), el visitador acude a Belorado, villa en la que entonces residía la audiencia de ese adelantamiento, y ordena a algunos de sus oficiales, concretamente a tres receptores de su audiencia nombrados a tal fin, que recaben información sobre dos extremos ciertamente dudosos: los límites del distrito del adelantamiento burgalés y los lugares cabcza de jurisdicción "qure entran y se comprenden en el distrito del dicho adelantamiento» ${ }^{15}$. Al mismo tiempo, el visitador envía un mandamiento a numerosos lugares del adelantamiento ${ }^{16}$ solicitándoles toda la información necesaria para conocer su situación: a quién pertenece la jurisdicción, qué lugares le están sometidos, qué imposiciones se pagan, etc., son éstos algunos de los datos solicitados además de, como era de esperar, preguntarles por el comportamiento de los alcaldes mayores en su lugar. Las respuestas no se hacen espetar y Luján tecibe, por una parte y de sus oficiales, una minuciosa exposición de los límites del adelantamiento junto con un listado de las ciudades, villas y lugares comprendidos en él, un total de más de 350 lugares entre los que se incluyen los numerosos valles que se despliegan a lo largo y ancho de tan extenso distrito; por la otra, de cada uno de los lugares requeridos por el mandamiento, cumplida respuesta a las preguntas que en él se encerraban. Con unas y otras (la documentación de las visitas se ha revelado como la fuente más rica para el conocimiento de los adelantamientos modernos) he elaborado la relación que presentaré a continuación y que no es otra cosa que - a mi entender - un interesante bosquejo del mapa señorial, de sus titulares y de la complejidad y riqueza que ese mundo encierra; todo ello en el marco del adelantamiento de Burgos en el año 1598.

configurado así como un procedimiento de carácter extraotdinario y naturaleza inquisitiva, sustanciado ante un delegado regio en dos fases -la una instructoria y la otra contradictoria- de manera antiformalista y rigurosamente secreta, y determinado en única instancia (fase resolutoria) por el rey con la finalidad de controlar y corregir o reformar el funcionamiento de las Chancileráas, y de exigir o preparar la exigencia de responsabilidad a todos quienes la componían por su conducta antijuridicay (Génesis y formación bistórica de las visitas a las Chancillerias Castellanas (1484-1554), Tesis inédita, Universidad de Salamanca, 1989, III, págs. 1392-1393). Obviamente, aunque su historia esté inseparablemente ligada a la de las Chancillerias castellanas, éstas no fueton los únicos organismos visitados, si bien esta ampliación de objetivo llevó -como este mismo autor advierte- a la desnaturalización de alguna de las caracteristicas definitorias de su estructura institucional (ibid., pág. 1395). Tesis Doctoral en buena parte recogida en su libro Las Audiencia y las Chancillerias castellanas (1371-1525), Madrid, 1994, pero no en la parte a la que nos estamos refiriendo que resume brevemente en las págs. 425-428.

14 La Real (t.) Provisión (p.) tiene fecha de 24 de Diciembre de ese año (AGS-CC, 2767).

15 Se les ordena revisar todos los papeles y escrituras depositados en la audiencia, informarse por terceras personas, etc. (AGS-CC, 2767).

16 Hará lo mismo en los otros dos.

Hippania, LIX/2, núm. 202 (1999) 493-531 
Ni el espacio, ni el tiempo han sido elegidos al azar. El espacio se corresponde pues con el adelantamiento moderno de Castilla en el partido de Burgos ${ }^{17}$. Un extenso y variado territorio, heredero natural del adelantamiento bajomedieval de Castilla, sobre el que es necesario hacer algunas precisiones. Este adelantamiento de Burgos se configuró en los primeros años del siglo XVI, concretamente en 1502, al desdoblarse el territorio del antiguo adelantamiento de Castilla en dos, formándose los nuevos adelantamientos de Castilla partido de Burgos y de Castilla partido de Campos o, simplemente, en una denominación de uso frecuente, los adelantamientos de Burgos y de Campos (o Palencia). En el origen de la división estuvo la desmesurada extensión del adelantamiento castellano que amenazaba con hacer infructuosa la presencia del alcalde mayor ${ }^{18}$. La nueva fórmula para la organización del espacio era adecua$\mathrm{da}$, pero el tetritorio acotado excesivo para un sólo alcalde ${ }^{19}$. Junto a la extensión, también debió influir el incremento de la importancia económica y señorial de ese vasto territorio. Son tierras donde, a lo largo del siglo XV, se ha llevado a cabo una importante expansión señorial a la sombra del desorden político y de las consiguientes mercedes. Bartolomé Yun habla de la fuerte «expansión-geográfica del señoríon que sufrió la tierra de Campos en el siglo XV - y que seguiría en el XVI- con la implantación de los Fernández Velasco, Enríquez, Pimentel o la imparable de los Condes de Benavente, en esas «tierras cómodas para el cultivo, ricas en hombres, y cercanas a encrucijadas de mucho tránsito». Tierras de indudable valor en época de crisis económica y demográfica ${ }^{20}$. La conflictividad que se desata entre los señores y sus vasallos debido a la presión económica que se ejercía sobre ellos ${ }^{21}$, unido a la crisis política que se abre tras la muerte de Isabel, terminó por aconsejar el desdoblamiento.

17 Hemos elegido el de Burgos y no el de Campos, porque creemos que este úlimo territorio, desde el punto de vista señorial en la Edad Moderna, es mejor conocido, basta con citar la expléndida obra de B. YUN CASAlILLA, Sobre la transición al capitalismo en Castilla. Economia y sociedad en la tierra de Campos (1500-1830), Salamanca, 1987; o el interesante trabajo de L. FERNÁNDEZ MAŔín La venta de vasallos» entre el Pisuerga y el Cea en los siglos XVI y XVII», en Archivos Leoneser, $1982, \mathrm{n}^{\circ} 72$, págs. 293-393.

18 No sucedía lo mismo con el adelantamiento de León, discreto en su extensión, aproximadamente la mitad del castellano.

1) (Sepades que soy ynformado que a cabsa de la mucha tierra y población que ay en el adelantamiento de Castilla, la persona que tiene cargo de alcaldia del dicho adelantamiento no puede visytar todas las villas e lugares del como conviene ni faser todas las otras cosas que a su oficio es obligatorion (r.p. dada en Madrid, el 28 de noviembre de 1502, en AGS-RGS, noviembre, 1502 ).

20 Vid. la interesante exposición de este autor en Sobre la transizión al capiltalismo en Castilla. Economia y sociedad en tierra de Campos (1500-1830), Valladolid, 1987, principalmente págs. 69-90, la cita pertenece a la pág. 70 .

21 Bajo el epigrafe; «Reacción señorial, monarquia y conflictividad», YUN CASALILLA nos dibuja el complejo panorama de esos años, henchido de conflictos internobiliarios y de enfrentamientos entre señores y vasallos (ibid., págs. 86-90).

Hipania, LIX/2, núm. 202 (1999) 493-531 
El monarca se valió de las merindades menores, distritos en los que se encontraba subdividido el adelantamiento de Castilla ${ }^{22}$, para llevar a cabo la división. Así, las merindades menores de Villadiego, Campo (Aguilar de Campoo), Castrojeriz, Candemuño, Santo Domingo de Silos, Río de Uibierna, Montes de Oca, Bureba, La Rioja, Nájera y Logroño, conformaron el nuevo adelantamiento de Castilla partido de Burgos ${ }^{23}$.

Años después, probablemente en la década de los noventa, una nueva modificación vino a alterar la base espacial del adelantamiento de Burgos al tomarse la decisión de incluir en la órbita de los adelantamientos a las tierras de las extremaduras castellana y leonesa ${ }^{24}$, un espacio territorial que, hasta entonces, se había mantenido al margen de ellos ${ }^{25}$. En la base de esta medida, como no podia ser de otra manera, nos encontramos de nuevo con el mundo señotial. A lo largo de la Baja Edad Media, esta extensa franja territorial se había mantenido al margen de los adelantamientos gracias a su peculiar fisonomía de comunidades de Villa y Tierra. Pero, con el paso del tiempo, aquella fisonomía original se había ido desdibujando en la misma medida en la que se había ido extendiendo y afianzando en ella el régimen señorial ${ }^{26}$. Es verdad que siguen existiendo importantes y, a veces, extensos corregimientos, pero éstos, lo sabemos, no eran incompatibles con el avance meridional de los adelantamientos hasta encerrar en ellos a todas las tierras meseteñas.

Una vez separado del adelantamiento de Campos y tras la incorporación a él de las tierras sureñas situadas entre el Duero y el Sistema Central, el distrito del adelantamiento de Burgos vendría a corresponderse, más o menos, con el territorio de las actuales provincias de Santander, Burgos, La Rioja, Soria y la mitad oriental de la de Segovia ${ }^{27}$. Un amplio espacio en el que, geográficamen-

22 No se conoce bien el proceso de configuración de las merindades menores. En opinión de ÁlVAREZ BORGL, comenzaron a aparecer una vez constituidas las metindades mayores y su proceso de formación se llevó a cabo en los años finales del siglo XII y en los primeros de] XIII. Las merindades mayores eran distritos en los que, además de actuar los oficiales delegados de los adelantados, servían de referente para la recaudación de algunas rentas regias, como la moneda y el servicio, que pagaban por lo general todas las villas independientemente de su condición (Monarquia fexdal y organización territorial. Alfoces y merindades en Castilla (siglos X-XIV), Madrid, 1993, págs. $141-145$ y 179 y sigs.).

23 Asi figura en la r.p. de 28 de noviembre de 1502 en la que se lleva a cabo la división y se nombra al bachiller Sebastián de Villafaña alcalde mayor de ese partido. En 1506 sigue ejerciendo el mismo cargo sobre las mismas merindades (xp. dada en Valladolid, a 30 de julio de 1506; su transcripción está recogida en Las Actas de las Juntas Genorales de Alava, vol. V, págs. 295-297).

24 Probablemente en un intento de poner bajo la jurisdicción de los alcaldes mayores de adelantamiento todo el territorio al sur del Duero.

25 A lo largo de la Baja Edad Media la línea trazada por el tío Duero se habia erigido en el limite meridional de los adelantamientos de Castilla y León.

26 Proceso apuntado ya por MarTínez Llorente en Régimen jurídico de la Extremadura castellana medieval. Las comunidades de villa y tierra (s. X-XIV), Valladolid, 1990, págs. 35-41.

27 Es posible precisar más aún los límites del adelantamiento burgalés. Limites que vendría marcados por una linea que, partiendo del puerto de San Vicente en plena costa Cantábri-

Hispaniu, LIX/2, núm. 202 (1999) 493-5.31 
te hablando, no existe una unidad física 28 .

El territorio así acotado nos muestra los límites externos del espacio geográfico articulado por el monarca para proyectar su dominio a través de la figura del alcalde mayor de adelantamiento. Pero estos límites extcrnos, siendo imprescindibles, no son suficientes para conocer el distrito jur... diccional del

ca, descendía en dirección sur hacia los valles de Baldeliga, Ruinasa y San Vicintc; valles, todos ellos, limítrofes con el adelantamiento de Campos (hasta tal punto, que los alcaldes mayores tanto del adelantamiento de Burgos como del de Campos, poseían jurisdicción a prevención sobre ellos ). Desde allí, proseguia el desceso por el valte de Cabuérniga incluyendo los siete valles de la montaña que pertenecían a la jurisdicción de Santillana, hasta llegar a las villas de Espinilla y Argeso, para, desde allí, atravesando el corregimiento de Reinosa, llegar a la villa de Aguilar, cuya jurisdicción quedaba toda ella incluida en la del adelantamiento burgalés. La linea continuaba su descenso, siguiendo ahora el curso del río Pisuerga, hasta la villa de Melgar de Fermental y, más al sur aun, las de Lantadilla, Bobadilla y Santoyo. A la altura de Quintanar del Puente, se adentraba, siguiendo el cauce del róo Arlanzón, hasta Villodrigo y Villaverde Mogino, para, desde alli, dejando fuera la villa de Palenzuela con toda su jurisdicción, seguir su camino en busca del rio Duero, incluyendo en su distrito los términos de las villas de Santa María del Campo, Villahoz, Torrepadre, Espinosa de Cerrato, Villafruela, Sotillo de la Rivera y Gumiel del Mercado. Ya en la otra ribera del Duero, atravesaba los términos del corregimien to de Aranda del Duero descendía hacia el sur incluyendo en su distrito los términos de Sagramenia, Fuentidueña, Aguilafuente, Berganzones, Turuégano, San Pedro de Yanguas y Sotosaltos hasta encontrarse con la Sierra que sube desde Segovia. Prosigue su recorrido por las cumbres de la sierra de Guadarrama, puerto de Somosierra y sierra de Ayllón, desde donde desciende hacia la villa de Galve. De alli a Cañamones, para continuar por las cumbres hasta el reino de Aragón que le sirve de límite. Pertenecian asi a este adelantamiento la ciudad de Sigenza y su tierra, Medinaceli con la suya, Deza, Ciria y Borobia. Continúa su ascensión, limitando con el reino de Navarra, atraviesa el corregimiento de Calahorra e incluye las villas de Ausejo y Alcanadre junto con toda la comarca de Logroño y sus montañas. Más al norte, bordea toda Castilla la Vieja hasta llegar a Medina del Pomar, Espinosa de los Montes, los valles de Soba y Ruesga y atraviesa la merindad de Trasmiera confinando con las cuatto villas de la costa del mar (Santander, Latedo, Castro-Urdiales y SanVicente de la Barquera que forman un corregimiento). Sube hasta Sartoria y, desde allí, siguiendo la costa, alcanza la villa de Comillas, para morir en el puerto de San Vicente, lugar desde el que partiamos (ibid., fols. 62-63). Conscientemente, hemos dejado fuera del distrito de este adelantamiento a las Hermandades de Alava. No porque sean ajenas a él, sino porque su inclusión plantea algunos problemas en el tiempo que será necesario dilucidar. De hecho, los autores de la relación que sirve de base a estas líneas, defienden su pertenencia a la jurisdicción de este adelantamiento, aunque reconocen que por diversos motivos no se ha usado de ella en los últimos años (ibid., fol. $62 \mathrm{v}^{\circ}$ ).

28 Efectivamente, no hay una unidad física en el tertitotio delimitado. Existe un cinturón montañoso al norte, una plataforma de unos $800 \mathrm{~m}$. de altitud media en el centro de Castilla y un nuevo cinturón montanoso en la zona suroeste. Zona montañosa es también la que cierra el paso hacia la Rioja. La gran plataforma castellana es atravesada, en su centro, por el río Dueto que corre camino del Átlantico. El cinturón montañoso del norte dificulta la entrada de las borrascas atlánticas hasta la plataforma interior originando una Cantabria húmeda y una Castilla de clima continental . La gran plataforma interior es el resultado de una cuenca rellenada por sedimentos de costras calcáreas que se continúan con las zonas montañosas de Burgos hacia la Rioja. El resto de la cuenca son arenas y arcillas. El hombre explota este substrato geológico con bosques y pastizales que fomentan el desartollo de una ganadería extensiva al norte y centro de la gran plataforma. Cultivos y viñedos es lo que más se explota en la zona de la Rioja.

Hipania, LIX/2, núm. 202 (1909) 493-531 
adelantamiento, porque no todo el territorio comprendido formó parte de él. Hemos de excluir, en primer lugar, los corregimientos, entendidos también como distritos territoriales más o menos amplios, como espacios de dominación ejercida mediante la figura del corregidor. En este sentido, y sólo en éste, podríamos decir que el alcalde mayor de adelantamiento se configuró en el tránsito del siglo XVI al XVII como "complemento» del corregidor. Dentro de aquellos límites, los distritos de uno y otro se confrguran por exclusión. La idea era clara y sencilla: sería adelantamiento todo aquello que no fuera corregimiento, corregimiento de realengo. De tal manera que, independientemente de su condición, todas los lugares dentro de los límites del adelantamiento de Burgos que no se hallaran integrados en un corregimiento, eran considerados automáticamente bajo la jurisdicción del alcalde mayor del adelantamiento. Castillo de Bovadilla nos habla de hasta un total de once corregimientos en el territorio que nos interesa ${ }^{29}$, los de Burgos, Soria, Segovia, Aranda-Sepúlveda, Logroño-Calahorra-Alfaro-La Guardia, Agreda, Atienza-Molina, Santo Domingo de la Calzada, Las Cuatro Villas, Siete Merindades ${ }^{30}$ y Campo de Reinosa ${ }^{31}$. Pero el conocimiento de su número y de su situación, al desconocer su extensión, no nos sirven para establecer los límites internos del adelantamiento burgalés. Será la propia documentación de los adelantamientos, en este extremo más locuaz, la que nos ayude en esta empresa. Después, podremos aprovechar los tesultados obtenidos para progresar en el conocimiento de los territorios de corregimiento ya que, volviendo la oración por pasiva, podremos decir que en ese gran distrito todo lo que no es adelantamiento, es corregimiento.

Para fijar el distrito jurisdiccional del adelantamiento de Burgos utilizaré el listado de lugares presentado por los oficiales de la audiencia de dicho adelantamiento a petición de Luján. En él, en principio, figuran todos los lugares que, siendo cabezas de jurisdicción, «entran y se comprenden en el distrito del dicho adelantamiento" ${ }^{32}$, aunque es necesario anunciar que, ni son todas los que están, ni están todas los que son.

29) Politica para corregidores y señores de vasallos, en tiempo de paz y de guerra, y para juezes erlesiásticos y seglares, y de Sacas, Aduanas, y de Residentias, y sus oficiales: y para Regidores, y Abogados, y del valor de los Corregimientos, $y$ Goviernos Realengos, y de las Ondenes, Amberes, 1704 (ed. facsimil, con estudio preliminar de B. González Alonso, 2 vols., Madrid, 1978).

30 Es todavía muy confuso el alcalce y la configuración de esta circunscripción administrativa denominada de las Siete Merindades, aunque gracias a los trabajos de Garci SAinz bi: BARANDA y DitzZ DI: SALAZAR o el último de SÁncI ILZZ Doningo (Las Merindades de Castilla Vieja y su Junta Gentral) se va avanzando en su conocimiento. En todo caso estamos convencidos de que hasta que la Corona no rescata la jurisdicción de las Siete Merindades tras la mucrte de Pedro Fernández de Velasco y crea el corregimiento que lleva ese nombre, los lugares que lo componen se encontraban bajo la jurisdicción del alcalde mayor del adelantamiento de Burgos.

31 No aparece en la relación de corregimientos de 1515 (AGS-Diversos de Castilla, 1. 9. fol. 39, recogida por G(JNZALIYZ AJ.ONSO en E/ Corregidor castellano (1348-1808), Nadrid, 1970, pág. 238).

32 El visitador les había ordenado que zevisaran todos los papeles y escrituras depositados en la audiencia, se informaran por terceras personas e hicieran todo lo necesario para su correcta elaboración (AGS-CC, 2767). 
No son todas las que están, aunque sí casi todas. Hasta donde alcanza nuestra información, deberíamos excluir en primer lugar a Fresnillo de las Dueñas. Esta villa, que había pertenecido al monasterio de Nuestra Señora de la Vid de la Orden de Premoste, fue incorporada a la Corona real y vendida con su jurisdicción civil y criminal al concejo de la propia villa en 1555; después fue agregada al corregimiento de Aranda de Duero. Tal vez habría que excluir también a la villa de Miedes de Atienza, situada en el Obispado de Sigüenza (Guadalajara), que niega su pertenencia al adelantamiento y defiende su postura ante el Consejo en el pleito que contra el alcalde mayor del adelantamiento mantiene precisamente en esos momentos ${ }^{33}$. Otras villas, como por ejemplo Pesadas, intentan libratse de su jurisdicción alegando estar en posesión de algún privilegio ${ }^{34}$. Alguna, como Atienza, esgrime como razón el hallarse apartadas de los límites de la jurisdicción del alcalde mayor de adelantamiento ${ }^{35}$. Por último, no deberian figurar en la relación que presentamos ni el Valle de Valdelucio, ni la villa de Castroserna de Abajo al no poseer ninguno de ellos jurisdicción propia, requisito imprescindible para ser considerados cabezas de jurisdicción.

$\mathrm{Si}$, como acabamos de ver, no son todos los que están, tampoco están todos los que son. Las ausencias no parecen preocupar excesivamente a los autores de la referida relación; se curan en salud recordando que los posibles olvidos no podrian considerarse nunca lugares exentos puesto que, como ya ha quedado apuntado, dentro de los límites marcados, todo lo que no era corregimiento de realengo había de ser considerado bajo la jurisdicción del adelantamiento ${ }^{36}$. $\mathrm{Si}$ a los relatores no les preocupó, tampoco a nosotros, aunque me haya ocupado el sacar de su olvido a algunos de aquellos lugares como, por ejemplo, Banoos de Valdearados, Barahona, Cabezón de la Sierra, Castro de Peones, Santona y su puerto y así hasta una docena ${ }^{37}$.

El conjunto de todos los lugares que aparecen en la relación, una vez situados en el mapa, nos dará una imagen bastante aproximada de la jurisdicción del adelantamiento y, por exclusión, aunque no sea ahora objeto de nuestro interés, también la de los corregimientos enclavados en ese territorio. Pero aún es posible perfilar más esa imagen. Recordemos el criterio seguido a la hora de incluir los lugares en la relación, su presencia estaba justificada en razón de su condición de "cabeza de jurisdicción», en razón de ser una villa "cabecera» y, por lo tanto, formar un concejo, tener jurisdicción y poseer oficiales propios. Es verdad que la jurisdicción de muchos de los lugares que aparecen en el listado se agotaba en sí mismos al no tener bajo su jurisdicción a ningún otro lu-

\footnotetext{
33 AGS-CC, 2767 , fols. $450-454 v^{\circ}$.

${ }_{34}$ Sobre ello se sigue pleito en el Consejo (ibid., 2767, fol. 61).

35 También en el Consejo Real hay pendiente un pleito de la villa y su señor contra dicho alcalde mayor (ibid., 2767, fols. 390-395).

36 Ibid., fol. $61 \mathrm{v}^{\circ}$.

37 Al final de la relación presentada se añaden hasta un total de once lugares silenciados en aquella que, sin duda, pertenecen a la jursdicción del adelantamiento de Burgos.
}

Hihpunti, L.JX/2, núm. 202 (1999) 493-531 
gar o aldea ${ }^{38}$; pero había otros muchos cuya jurisdicción se extendía más allá, abarcando a un número considerable de lugares y aldeas que les estaban sometidas, adquiriendo así una especial dimensión «su tierra». De entre ellos, como veremos, cabe destacar, por el número de lugares a él sometidos y por la complejidad de dicho sometimiento, la villa de Cerezo de Río Tirón, cerca de Santo Domingo de la Calzada, a medio camino entre Burgos y Logroño; la villa de Almazán, que desplegaba su jurisdicción sobre un total de cuarenta lugares; o Ia de Muño, que rondaba la treintena, etc.

El espacio así delimitado se corresponde con el distrito del adelantamiento de Burgos en el año de 1598. Aunque quedan planteados algunos problemas ${ }^{3}$, creemos que, salvando la creación de nuevos corregimientos o la separación de algún lugar que por una u otra vía consiguiera de detecho o de hecho eximirse de Ia jurisdicción del alcalde mayor ${ }^{40}$, no debió sufrir alteraciones sustanciales hasta el momento de su agregación, ocurrida casi a mediados del siglo XVII.

A continuación, haremos hincapié en la significación del año concreto en el que se dibujan estos límites: 1598. Es verdad que nos detenemos en él obligados por la documentación al set entonces cuando se recaba la información; pero, siendo así, lo cierto es que no se trata de un momento cualquiera y menos en relación con la evolución del señotío. 1598 es el año en el que se cierra el reinado de Felipe II, aquél rey que, como recordábamos, no dudara en calificar a sus alcaldes mayores de adelantamiento de "freno de los señores»" ${ }^{4 i}$ pero que, al tiempo, impulsara con fuerza el proceso de señorialización en el ámbito rural castellano; proceso que heredara de su predecesor.

38 No tenian bajo su jurisdicción ningún lugar, entre otras, las siguientes villas: Almaluez, Anguiano, Arraya, Ausejo, Baños de Valdearados, Brieva, Cabezón de la Sierra, Cabrejas del Pinar, Canales, Canicosa, Castro de Peones, Ciadonclia, Cigudosa, Frandobiñez, Fresneda, Fresnillo, Gallinero, Gómara, Grisaleña, Hacinas, Hontoria de la Cantera, Hontoria de Valdearados, Huércanos, Iglesias, Leza, Madrigal del Monte, Mansilla, Monasterio de Rodilla, Montenegro, Neila, Palacios de la Sierra, Pedroso, Poza (tan sólo dos granjas de molino: Lago y Navafuente), Quintanar de la Sierra, Rabanera, Retortillo, Salazar de Amaya, Sojuela, Soto, Tardajos, Trevijano, Utrilla, Veganzones, Velamazân, Ventrosa, Villavelayo, Villezmalo, Vinegra de Suso y Vinegra de Yuso.

3.) Ya hemos hablado de las Siete Merindades y al menos habremos de dejar planteado el problema del territorio de las Hermandades de Alava, territorio que, como afirman los relatores, es de la jurisdicción del alcalde mayor del adelantamiento de Burgos por ser todo él de condición señorial, aunque en los últimos años no la hayan podido ejercer debido a que una ejecutoria en la que se confirmaba su jurisdicción habia sido sobreseida por motivos que no explican (ibid, fol. $61 v^{\circ}$ ). La relación existente entre este territorio y el adelantamiento de Burgos a lo largo de los siglos XIII al XVI es ciertamente compleja y necesita ser estudiada.

40 El caso más llamativo, aunque tardio por suceder en el reinado de Felipe IV, es el privilegio de exención de la jurisdicción del adelantamiento de Burgos que este monarca da a numerosos lugares de la merindad de la Bureba sometidos a la jurisdicción de las villas de Briviesca, Pancorbo, Cerezo y Oña (transcripción hecha por CADINANos BARIsCl, El adelantamiento de Castilla, partido de Burgos: sus ordenanzas y arbivo, Madrid, 1989).

41 AGS-CC, 1083,56 
En 1598 se habían efectuado ya, bajo los reinados de Carlos I y Felipe II, las ventas de pueblos pertenecientes a las Ordenes Militares, monasterios e iglesias tan características del siglo XVI; como dejara escrito S. de Moxó, uno de los arbitrios ideados para paliar los desajustes de la Real Hacienda y que provocó ese «uápido tránsito - tras efímera incorporación a la Corona- del abadengo o ha encomienda, al laico señorio nobiliarios ${ }^{42}$, y no sólo a éste ${ }^{43}$. Las tierras del adelantamiento de Burgos fueron escenario privilegiado de estas desamortizaciones; podemos seguir su rastro, el proceso secularizador de numerosas villas y lugares pertenecientes a diversas Iglesias y Monasterios ${ }^{44}$. Así, la villa de Fresnillo, o las de Canicosa y Quintanar de la Sierra, nos sirven como ejemplos de la aplicación de la Bula dada al Emperador por el Papa Julio III en 1551. Fresnillo, que pertenecía al Monasterio de Nuestra Señora de la Vid de la Orden de Premoste, fue eximida e incorporada a la Corona real para, a continuación, en 1555, vender al propio concejo de la villa su jurisdicción civil y criminal ${ }^{45}$. Como ya quedó apuntado, Fresnillo salió de la jurisdicción del alcalde mayor del adelantamiento de Burgos en el momento en el que el rey la incorporó al corregimiento de Aranda de Duero ${ }^{4}$. Por su parte, Canicosa, San Leonardo, Hontoria del Pinar, Miranda del Pinar y Rabanera, todas ellas pertenecientes al Monasterio de San Pedro de Arlanza, fueron separadas de él y vendidas respectivamente a D. Juan Mantique de Lara, en $1566^{47}$, y a D. Juan Asenjo, en $1573^{48}$.

La posterior Bula dada por Gregorio XIII en 1574 a Felipe II, dejó también su impronta en nuestro territorio. De la Mesa Arzobispal de Toledo se desgajaron, entre ottas, las villas de Almaluez y Utrilla que pasaron a manos del duque de Medinaceli entre 1574 y $1575^{49}$. De la Mesa Arzobispal de Osma salieron, por ejemplo, las villas de Cabrejas del Pinar y Gómara, ambas, tras ser incorporadas brevemente a la Corona, se compraron a sí mismas en torno al año $1580^{\text {50. }}$. Santoña y su puerto fueron eximidas del señorío y vasallaje del

42 "Las desamortizaciones eclesiásticas en el siglo XV", AHDE, 31, 1961, p. 328.

43 Ya que los compradores no siempre fueron nobles como tendremos oportunidad de comprobar.

44 Sobre la consecución de las autorizaciones pontificias véase FERNÁNDI: MIARTín, «La venta de vasallos» entre el Pisuerga y al Cea en los siglos XVI y XVII", cn Archivor Leoneses, nü72, 1982, págs. 314 y sigs.

45 Sabemos que un año después, la Infanta Doña Juana, Gobemadora del Reino segregó de ese mismo Monasterio la villa de Fuente el Césped que, en 1607, Felipe III vendería al conde de Miranda, presidente del Consejo (Moxó, «Las desamortizaciones eclesiásticas», pág. 350), de quéén ya era la villa de Haza y su tierra (AGS-CC, 2764, fols. 341-343).

46 Nos llama la atención ver como dicho corregidor tenía facultad, no sólo para conocer en primera instancia, sino también en grado de apelació de los alcaldes ordinarios de la villa (ibid. , fols. 306-309).

47 Ibid, fols. 315-317, 347-349vú y 372-374. Véase también, Moxó, «Las ventas de alcabalas en los reinados de Carlos I y Felipe II", en $A H D E, 41,1971$, pág. 515.

48 Según los datos aportados por Moxó» en "Las desamortizaciones eclesiásticas», pág. 351. También, AGS-CC, 2764 , fols. 280-282.

4) Ibid., fols. 407-418.

51) Ibid, fols. 375-379 y 447-449.

Hi.poniu, LIX/2, núm. $202(1999)$ 493-531 
Monasterio de Santa María la Real, quedando incorporadas a la Corona a cambio de una cierta cantidad de maravedies ${ }^{51}$. Del Monasterio de Nájera se desmembraton las villas de Nestares, Huercanos y Lagunilla ${ }^{52}$. Riaza de la Sierra pasó de la Iglesia Mayor de Segovia a las manos del marqués de Maqued:1 ${ }^{53}$, ctc. Pero dejémoslo aquí porque, en estos casos y a los efectos que a nosotros nos interesan, no sc trata tanto de un incremento del señorío como de un cambio en la titularidad que, en ocasiones, benefició al tealengo.

Más no sólo se vendieron pueblos pertenecientes a monasterios y obispados. Cuando llegamos a 1598, los Austrias mayores habían desgajado ya de su Corona real numerosas villas y lugares, pueblos que cambiaron su condición realenga por la señorial; son los señoríos de nueva creación. En el marco de nuestro adelantamiento, Castroserna de Arriba, Castroserna de Abajo y Ventosilla, que pertenecía a la villa de Sepúlveda, fueron vendidas a D. Gaspar Durango, consejero del rey ${ }^{54}$. La villa de Leza y la de Trevijano, fueron compradas al tey por D. Marcos Guerreto, su consejero además de oidor de su Corte y de la Audiencia de Méjico ${ }^{55}$. Por su parte, la villa de El Peral pasaba a manos de Juan Curiel de la Torre ${ }^{56}$. O las de Boceguillas y Verganzones, ejemplo claro de aquellos lugares que, puestos en venta por el rey, se compraton con su jurisdicción ${ }^{57}$.

En esta espiral de ventas quedaron también atrapadas numerosas rentas reales, en especial las alcabalas. Dentro de nuestro distrito, en la mayoría de los señorios de nueva creación, asi como en aquellos que habían sido secularizados, se vendieron sus alcabalas, consideradas ya, a finales de este siglo XVI, como una "preciada regalía» del régimen señorial ${ }^{58}$. Con los datos que poseemos, podemos afirmar que en 1598 al menos se habían enajenado en torno a un $40 \%$ de las alcabalas de las villas y lugares cabeza de jurisdicción pertenecientes al adelantamiento de Burgos ${ }^{59}$. En la mayoría de los casos es el titular del señorío quien percibe el montante de las alcabalas, pero no siempre es así. Fijémonos, por ejemplo, en las villas de Canicosa y Cabezón de la Sierra, señoríos jurisdiccionales pertenecientes a D. Antonio Manrique de Lara, sus alcabalas, al igual que sus tercias, pertenecín al Condestable de Castilla. En Nestares, señorio jurisdiccional de $\mathrm{D}$. Martín de Rivera, las alcabalas no las percibía ni del rey, ni del señor, sino la villa por compra que de ellas hicieran en su dia al rey (x).

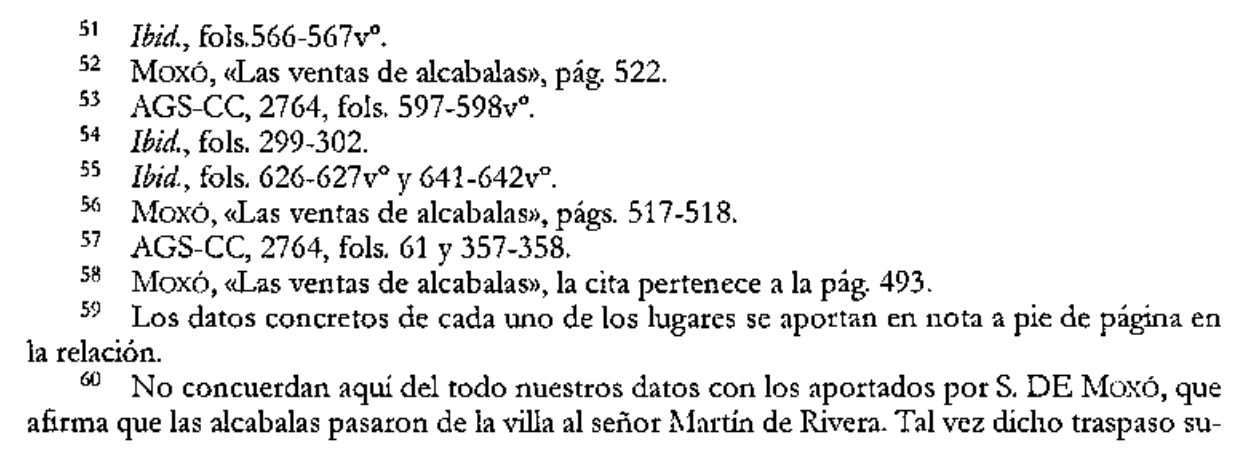


Si, como acabamos de ver, en 1598 se había producido ya un importante proceso de señorialización en el ámbito rural castellano "1, estaban, sin embargo, por llegar las númerosas ventas de vasallos realizadas en los siguientes reinados, especialmente en el de Felipe IV ${ }^{62}$. Cuando esto ocurra, se hablará de "refeudalización» "63, de apogeo del poder señorial en este siglo XVII ${ }^{64} \mathrm{y}$ será entonces cuando, guiados por otros criterios, cobrarán sentido los cambios que se introducirán en la organización de los adelantamientos, pero todo ello queda ya fuera de nuestras fronteras temporales. Por eso, volvamos al objetivo que nos proponiamos: dejar constancia del peso que el señorío tenía en el distrito del adelantamiento de Burgos a la muerte del rey Felipe II. Utilizaremos para ello como base la extensa relación de los lugares sujetos a la jurisdicción del adelantamiento que se elaboró con motivo de la visita de Luján, señalando después, siempre que nos sea posible, su condición y su titularidad.

Bajo la jurisdicción del adelantamientode Burgos se encontraban unos 355 lugares cabezas de jurisdicción. Conocemos la condición, realenga o señotial de un $40 \%$ de ellos; tanto por ciento que consideramos aceptable para que la imagen proyectada sea suficientemente significativa. Pues bien, de ese $40 \%$, nada menos que aproximadamente el $86 \%$ corresponde a villas o lugares de jurisdicción señorial en cualquiera de sus modalidades.

Todos estos datos quedan reflejados en la relación anunciada. No son sólo cifras. Son, permítaseme reiterarlo, un bosquejo del mapa señorial del momento, de sus titulares y de la complejidad y riqueza que ese mundo encierra.

Hemos de llamar la atención sobre el criterio seguido en la elaboración de esta información. En la primera de las columnas aparecen por orden alfabético ${ }^{65}$ el nombre de las ciudades (las menos), villas (las más) y valies situados bajo la jurisdicción del alcalde mayor del adelantamiento de Burgos. No obstante, al constatar, como ya se ha puesto de manifiesto, la ausencia de algunos lugares, hemos incluido una lista complementatia que aparece a continuación de la

cedió con posterioridad a $1598 \mathrm{o}$, tal vez, la villas interesadamente no dió noticia de él al visitador (AGS-CC, 2767, fols. 434-436 y Moxó, «Las ventas de alcabalas», pág. 522).

61 Moxó, «Las ventas de alcabalas», pág. 535.

62 La venta de pueblos de realengo, que hasta entonces se habia hecho de forma esporádica, se convirtió en operación planeada y masiva en el reinado de Felipe IV: fue, sin duda, uno de los hechos más desafortunados y en su génesis concurrieron, de un lado, las imperiosas necesidades de la Real Hacienda, y de otro, la abundante demanda por parte de miembros de la nobleza media y de la burguesía que veían en la adquisición de un señonio un medio de promoción social, un paso muy firme hacia la concesión de un título nobiliario en un tiempo en la que ya se cotizaba poco la simple hidalgua»" (DOMiNGuIZ ORTr, «El régimen señorial bajo los últimos Austrias", en Historia de España de Menéndez Pidal, t. XXIII, págs. 574-575).

63 Baste con citar aquí el trabajo de I. AIIIENZA HLRNÁNDL\%, «Refeudalización» en Castilla durante el siglo XVII: çun tópicom, en AHDE, 56, 1986, págs. 889-920.

64 Véase Gonzílez Aionso, «Notas sobre las relaciones del Estado..., págs. 365-394, concretamente: 385 .

65 Hemos respetado la ortografia original del documento, regularizando las mayúsculas.

Hispania, 1.IX/2, núm 202 (1999) 493-531 
principal y a la que, probablemente, podrán añadirse en el futuro nuevos nombres. En una segunda columna, con el fin de facilitar su localización, aparecen esos mismos lugares con su denominación actual. La tercera de las columnas, que es a nuestro entender la fundamental, el núcleo de estas líneas, refleja el tipo de jurisdicción a la que se hallaban sometidos los distintos lugares. En una clasificación de no siempre fácil factura por la variedadad de las situaciones, se diferencia el realengo del señorío y, dentro de éste último, sus distintas modalidades: señorío eclesiástico (E.), cuando el titular de dicha jurisdicción es una iglesia o un monasterio; laico (L), cuando pertenece a un noble o a una persona que sin serlo haya accedido a él, normalmente medinnte compra; y concejil (C.), cuando la jurisdicción pertenezca a la propia villa, por compra o por privilegio real. En nota a pie de página se añaden otros datos que consideramos de interés para profundizar en la administración señorial: el tipo de oficiales que ejercen la jurisdicción, en nombre de quién la ejercen, quién los nombra, a quién pertenecen las distintas imposiciones existentes y, en caso de secularizaciones, su procedencia, su venta, etc. En una cuarta columna aparecen los titulares del señorío correspondiente. Esta columna exige una importante precisión sin la cual pudiéramos, no sólo inducir al error, sino también perdernos parte de esa tiqueza que, como venimos afirmando, tiene el mundo señorial. Cuando hablamos de titulares, nos estamos refiriendo a los titulares del señorío solariego - por expresarlo con terminologia tradicionaly no, aunque en la mayoría de los casos pueda coincidir, a los titulares de la jurisdicción. Es precisamente en la combinación de los datos aportados en estas dos últimas columnas donde mejor se nos revela la magnitud, la complejidad y la diversidad del mundo señorial.

En primer lugar debe destacarse su extensión frente a un adelgazado realengo, estamos hablando de más de un ochenta y seis por ciento de los lugares cuya condición nos es conocida ${ }^{60}$. En ningún momento pretendemos trasladar la proporción que reflejan estos datos conocidos (por las respuestas dadas por los propios lugates a los requerimientos del visitador), a los lugares cuya condición desconocemos. Entre otras cosas, se nos podría argumentar que a Luján, tal vez, sólo le interesó recabar información de los lugares de señorío al ser su intención principal la de averiguar el comportamiento de los alcaldes mayores en ese tipo de territorios. Pero sin necesidad de forzar inecesarias extensiones, es indudable que entre los lugares no clasificados los había también de señorio, baste con hacer un recuento de los lugares del adelantamiento de Burgos pertenecientes al señorío de abadengo a mediados del siglo XVI ${ }^{67}$. Sea como fuete, los datos que tenemos están ahí, manifestando un profundo dese-

66 Más aún del reflejado por $\mathrm{H}$. KAMEN en el mapa de las jurisdicciones en Castilla la Vieja (Una sociedad conflictiva: España, 1469-1714, Madrid, 1984, pág. 459.

67 Relación enviada por el alcalde mayor del adelantamiento de Castilla partido de Burgos, en respuesta a la Real Cédula de 10 de diciembre de 1552 en la que se pide, entre otras cosas, la relación de todos los lugares que en su demarcación pertenecen a monasterios (Para la edición y estudio de estas informaciones véase M. L. Alonso MARTín y M. L. PA.ACIOS, Jurisditción, gobierno y bacienda en el señorio de abadengo castellano en el siglo XVI, Madrid, 1993.

Hi.pathia, I.IX/2, núm. 202 (1999) 493-531 
quilibrio en favor del señorío y, dentro de éste, del señorío laico en beneficio de personajes tan podetosos como el Condestable de Castilla, el conde de Aguilar o el marqués de Villena. Tan larga relación de lugares, además de evidenciar la presencia cuantitativa del señorí, pone de manifiesto, como venimos repitiendo desde el principio, su riqueza y complejidad. Y es que, junto a los señoríos más comunes, aquellos en las que el señorio solariego y el jurisdiccional coinciden en un mismo titulat, nos encontamos con otros en los que la titularidad se encuentra dividida. Ésta es una situación que se repite con cierta frecuencia en lugares bajo el señorío del conde de Aguilar. Así vemos cómo Brieva de Cameros, Canales de la Sierra, Mansilla, Montenegro, Ventrosa, Viniegra de Yuso o Villavelayo son villas pertenecientes al señorio del conde de Aguilar que, como tal señor, recibe ciertas prestaciones económicas como la martiniega o la merindad, pero cuya jurisdicción no le pertenece por estar en manos del rey. Tampoco le pertenece la de Villanueva de Cameros, aunque en este caso no sea su titular el rey, sino la propia villa. Éstos no son los únicos casos. Viniegra de Suso, cuya jurisdicción pertenece al rey, es una villa del señorío del duque de Alba. Una situación opuesta encontramos en la villa de Huércanos que, siendo de la Corona real, tiene una situación jurisdiccional un tanto peculiar al encontrarse dividida ésta entre la ciudad de Nájera, señorío de duque de Nájera (civil), y la propia villa (criminal) siempre a prevención con la ciudad de Nájera. En situación parecida se en-. cuentra Madrigal del Monte. La posición más compleja tal vez sea la de Cerezo de Riotirón cuyo señor, el Condestable de Castilla, es el titular de su jurisdicción. Esta villa, a medio carmino entre Burgos y Logroño, tenía nueve lugates aforados a su jurisdicción civil y criminal, y hasta un total de ventisiete sujetos tan sólo a la civil. La mayoría de estos últimos nombraban a sus propios alcaldes ordinarios que tenían capacidad para juzgar hasta los cuatrocientos $\mathrm{mrs}$. De todos estos lugares con este tipo de sujeción, tan sólo nueve eran vasallos del Condestable, el resto lo eran del rey.

En varios casos a lo largo de la relación hablamos de señorío concejil. Se trata de aquellas villas que afirman haberse comprado al rey, por lo que disfrutan de jurisdicción civil y criminal, alta y baja, mero y mixto imperio. Esta jurisdicción la ejercen a través de los alcaldes ordinarios que ellos mismos nombran. Es el caso de Veganzones o de Cabrejas del Pinar o de Gómara entre otras posibles villas. Obviamente, no es en la capacidad de nombrar a sus propios alcaldes ordinatios el criterio que nos lleva a incluir un lugar en una determina categoría, puesto que en muchos casos el nombramiento de los alcaldes ordinarios se encuenta en manos de la villa sin que ello presuponga la posesión de su jurisdicción. La declaración de la propia villa o la atribución de las penas de cámara son otros posibles argumentos a tener en cuenta. Pero, volviendo al nombramiento de los alcalde ordinarios por el concejo de la villa, podremos también contemplar a esas justicias, nombradas por la villa, ejerciendo la jurisdicción no en su nombre sino en el del rey a quien pertenece. Sirvan como ejemplo las villas de Ventrosa, Gallinero, o Mansilla, todas ellas nombran a sus justicias siendo de jurisdicción realenga. Obsérvese

Iitpania, J.IX/2, núm. 202 (1999) 493-531 
que en los tres casos enumerados no coincide el titular de la jurisdicción con el titular de la villa.

Acabamos de ver una de las varias modalidades existentes a la hora de nombrar las justicias de un lugar: su nombramiento por el concejo sin posterior intervención de nadie, no es la única. En los lugares de señorio éstas se multiplican por lo que, junto a la que acabamos de considerar, cabía la posibilidad de que una vez nombrados por el concejo, necesitaran la confirmación del señor, o que éste tuviera que elegir entre los candidatos propuestos por la villa $o$, incluso, que el señor nombrara directamente a estos oficiales sin consultar con el concejo ${ }^{18}$.

Por encima de estas justicias ordinarias, nombradas anualmente para conocer la primera instancia en los lugares de señorio jurisdiccional, el señor establece sus propios órganos de justicia superior en las diferentes versiones posibles: alcalde mayor, gobernador e, incluso, coregidor, con el fin de conocer en apelación las sentencias dadas por estos alcaldes ordinatios y, en muchos casos, también en primera instancia a prevención con ellos. No nos es del todo desconocido el funcionamiento de la jurisdicción señorial, ni su entronque bajo la suprema jurisdicción del monarca ${ }^{69}$, lo que tal vez nos es más extraño, por desconocido, es el ensamblaje en esa arquitectura de la figuta del alcalde mayor del adelantamiento que, volvemos de nuevo al lugar del que partíamos, se articuló al servicio de la monarquía para el control del señorío. lación.

No nos alarguemos más. Hora es ya de presentar al lector la anunciada re-

\section{Villas o lugares cabeceras del adelantamiento de Burgos:}

$\begin{array}{llll}\text { VILLA O LUGAR } & \text { NOMBRE ACTUAL } & \text { JURISDIC. } & \text { TITULAR DEL SEÑORIO } \\ \text { Abbadia de Santander } & \text { Abadía de Santander } & & \\ \text { Abbadia de Santillana } & \text { Abadía de Santillana } & \text { Señorio E }{ }^{70} & \text { Nbad } \\ \text { Açofra } & \text { Azofra } & & \\ \text { Agonzillo } & \text { Agonzillo } & & \end{array}$

6B Todas y cada una de estas posibiliđades encuentran su realización en los lugares incluidos en la relación que presentamos. Vid. sobre este tema las reflexiones de A. M. GuHARTE en El régimen señorial en el siglo XVI, págs. $147 \mathrm{y}$ sigs.

6. GUILARTE, E/ régimen señorial ent el siglo XVI, págs. 191 y sigs.

70 Pertenecía al patronazgo real pero se encontraba cedida al abad de dicha abadía. Éste nombraba un alcalde ordinario para conocer privativamente las causas civiles y criminales. La abadía se quejaba de que los jueces de la villa de Santillana y los del valle de Reocin, que eran del duque del Infantado, se entrometian a conocer las causas privativas de la abadia (AGS-CC, 2764 , fols. $543-545$ ).

Hippania, LIX/2, núm. 202 (1999) 493-531 


\begin{tabular}{|c|c|c|c|}
\hline Aguilafuente & Aguilafuentc & Scñorío I. ${ }^{71}$ & Pcdro de Zưñiga \\
\hline Aguilar de Nama & Aguilar de Río Alhama & Scñorío I. ${ }^{72}$ & Conde de Aguilar \\
\hline Aguilar de Campo & Aguilar de Campoo & & \\
\hline Aguilcra & Aguilera, la & & \\
\hline Ajamill & $\Lambda$ jamil & & \\
\hline Alcanadre & Alcantadre & & \\
\hline Nlcoba de la Torre & Alcoba de la Torre & & \\
\hline Alco:zr & Alco\%ar & & \\
\hline Alcuçcro & Nlcocero de Mola & Realengo ${ }^{73}$ & Rey \\
\hline Alcuvilla de $A$ vellaneda & Alcubilla de Avellaneda & & \\
\hline Almacan & Amaxin & Schorio $]_{.}{ }^{74}$ & Narquećs de Nlmazátı \\
\hline Almaluez & Alamaluč & Scñorio la ${ }^{75}$ & Ducjue de Medinaceli \\
\hline Mluclda & Albcida de Ircgua & & \\
\hline Amaya & Nmaya & & \\
\hline Amcyugo & Amcyugo & & \\
\hline Anguciana & Anguciana & & \\
\hline Anguiano & Anguiano & Scñonío l: ${ }^{76}$ & $\mathrm{Mt}^{\prime \prime} \mathrm{de} \mathrm{N}^{2} \mathrm{~S}^{2} \mathrm{de}$ Valvancra \\
\hline Arcnillas & Arcuillas de Riopisuerga & & \\
\hline
\end{tabular}

71 Lugar secularizado de la dignidad arzobispal de Segovia. Las alcabalas las percibía el senor por compra desde 1538 (S. 1): Moxú, «La venta de alcabalas" $\mathrm{P} .496$ ).

72 Tenía un alcalde mayor nombrado por el conde. De él eran las penas de cámara. Del rey tan sólo el servicio ordinatio y extraordinario (AGS-CC, fols. $656-657 \mathrm{v}^{\circ}$ ).

73 Esta villa en realidad no poseía más jurisdicción que en materia civil hasta $400 \mathrm{mrs}$. merced a un cédula real. En los casos criminales estaba sujeta a la villa de Belorado y en los civiles a la de Cerezo. El rey percibía el servicio real y la alcabala, mientras que al Monasterio de las Huelgas se le pagaban $200 \mathrm{mrs}$. anualmente en concepto de infurción y martiniega (ibid., fols. 310-312).

74 La villa tenia dos alcaldes ordinarios que eran elegidos por el marqués de entre los varios presentados por ella. En ella residía el alcalde mayor nombrado por el señor que ejercía su oficio además de en la villa y su tierra, en todos los estados del marqués. El rey no poseía más que el servicio ordinario. Las penas de cámara eran del marqués (ibid., fols. 390-395).

75 Villa desmembrada de la Mitra arzobispal de Toledo, a la que había llegado por vía testamentaria, fue vendida al duque de Medinaceli en 1574 o en 1575 . La jurisdicción la ejercia el duque a través de un gobernador nombrado por él que conocía en primera instancia. La segunda instancia estaba en manos de un gobernador nombrado por el arzobispó de Toledo. La villa viene quejándose de haber sido despojada por el duque de su derecho a nombrar alcaldes ordinarios para la primera instancia, por lo que eran sentenciados siempre fuera de la villa infringiendo así las leyes del reino (Ordenamiento de Montalvo III. 2. 14, recogida en la Nueva Recopilación IV. 3. 8) que prohibían sacar a alguien de su propio fuero (ibid., fols. 412-418vo). El duque percibía las penas de cimara y las alcabalas, éstas últimas conseguidas en 1591 como pago y recompensa de las salinas de Alcaluudete y Saelices (S. DI: Moxó, «La venta de alcabalas", pág. 523).

${ }_{76}$ La villa nombraba anualmente un alcalde ordinario para la primera instancia. Por su parte, el abad nombraba un alcalde mayor que conocía en segunda instancia y en primera a prevención con el ordinario. Las penas de cámara de las sentencias dadas por el alcalde mayor eran del abad, mientras que las de las sentencias de los alcaldes ordinarios pertenecían a la villa que las aplicaba, entre otras cosas, para la reparación de caminos. Del rey eran las alcabalas y las tercias, al tiempo que recibia anualmente $45.000 \mathrm{mrs}$. por el servicio real (AGS-CC, 2764, fols. $512-516)$.

II.ppania, 1.1X/2, núm. 202 (1999) 493-531 


\begin{tabular}{|c|c|c|c|}
\hline Arenzana & Arenzana & & \\
\hline Arlanzon & Arlanzón & Señorío [i. 77 & $\mathrm{Mc}^{\prime \prime}$ de las I-Tuclgas \\
\hline Arncdillo & Arnedillo & & \\
\hline Arnedo & Arnedo & & \\
\hline Aro & Haro & & \\
\hline Arraya & Araya de Oca & Señorio L. 78 & Condestable de Castilla \\
\hline Arrubal & Arrubal & & \\
\hline Ausejo & Auscjo & Sct̃otio l. ${ }^{71}$ & J. Ramire de Arellano \\
\hline Autol & Autol & & \\
\hline Avejar & Abcjar & Senorio $C$. & Dicgo de Avinuesa \\
\hline Aylion & Ayllón & Scñorio J. $\$$ & Marqués de Villersa \\
\hline Ayoluengo & Ayolucngo & & \\
\hline Ayinas & Jacinas & & \\
\hline Badoconde & Vadocondes & & \\
\hline Badran & Badarán & Señorio li. ${ }^{81}$ & J'ray Jcrónimo de Salazar \\
\hline Bahabon & Bahabón de Esgucva & Scñorío ]. ${ }^{82}$ & Duque de Osuna \\
\hline Baldaliga, vallc de & Valdaliga, valle dc & & \\
\hline Baldelaguna & Valdelaguna, comarca & Realcngo 83 & Rcy \\
\hline Baldesamancas, valle de & & & \\
\hline Baldoscra & Baldoscra & & \\
\hline Balenrajo & & & \\
\hline
\end{tabular}

77 La villa eligín entre sus vecinos dos alcaldes ordinarios que necesitaban la confirmación de la abadesa. El monasterio nombraba a su vez un alcalde mayor para visitar la villa y sus lugares y tomar residencia a sus antecesores. Las penas de cámara se las repartian entre la villa y el monasterio, mientras que las alcabalas y las otras imposiciones pertenecín al rey (ibid., fols. 295-298).

78 Del condestable era la jurisdicción civil que ejercía mediante un alcalde mayor por él nombrado. La jurisdicción criminal era de la villa de Belorado. La villa de Arraya nombraba a su alcalde ordinario. Las alcabalas eran del condestable y del rey las tercias (ibid, fols. 275 $\left.277 \mathrm{v}^{\circ}\right)$.

79 Los alcaldes ordinarios los nombraba la villa. El señor ponía un alcalde mayor para la apelación y para la primera instancia acumulativamente y a prevención con los alcaldes ordinarios. Las penas de cámara pertenecían al señor; al rey: las alcabalas, la moneda forera y el servicio real (ibid., fols. $623-629 \mathrm{v}^{\circ}$ ).

80 Ayllón y todos los lugares del Condado de Santisteban (un total de 38) nombraban anualmente un alcalde mayor por el estado de los ciudadanos y otro por el de los hijosdalgo. El marqués, por su parte, ponía un gobernador y justicia mayor para todo el Condado. Suyas eran las penas de cámara y del rey el servicio real (ibit., fols. $595-596 \mathrm{v}^{\circ}$ ).

81 Calificamos la juriscicción de «abadengo" por ser su titular un frayle de la orden de San Agustín de la ciudad de Burgos, aunque creo necesario llamar la atención sobre el particular de que en ningún momento se hace referencia al abad, o a un monasterio. Fray Jerónimo de Salazar, el titular, nombraba tanto al alcalde ordinario como al gobernador y recibía las penas de cámara. Del rey eran tas alcabalas y el servicio teal (ibid., fols. 509-511).

82 La villa nombraba cuatro personas entre las que el duque o su gobernador elegian y confirmaban dos como alcaldes ordinarios. Del duque eran las penas de cámara y del rey el servicio real (ibid., fols. $278-279 \mathrm{v}^{\circ}$ ).

83 El valle nombraba anualmente dos alcaldes mayores que ejercian la jurisdicción por una ejecutoria bibrada por el Consejo. Suyas eran las penas de cámara. El rey percibía el servicio ordinario y extraordinario, así como la moneda forera. Las alcabalas y las tercias pertenecian al Condestable de Castilla (ibid., fols. 550-552vo). 


\begin{tabular}{|c|c|c|c|}
\hline Balgañon & Valgañón & & \\
\hline Ballucrcanes & Vallucrcancs & & \\
\hline \multicolumn{4}{|l|}{ Balvas } \\
\hline Bañares & Bañares & Scก̃ońo $\mathrm{J}^{84}$ & Duque de Bejar ${ }^{85}$ \\
\hline Baños de Rioja & Baños de l'ioja & & \\
\hline Baños de Riotouia & Baños de Río Tobía & & \\
\hline Baruadillo de l-Icreros & Barbadillo de los I-Ierreros & & \\
\hline Baruadilto de Mercado & Barbadillo de Mcrcado & & \\
\hline Beganzones & Veganzones & Scinorío C. ${ }^{86}$ & La villa \\
\hline Beguera & Viguera & & \\
\hline Belamazan & Velamazán & Señorio I. ${ }^{87}$ & Martín de Castrcjón Andrade \\
\hline Belorado & Belorado & & \\
\hline Beluimbre y barrio & Belbimbre y Barrio de Muñó & & \\
\hline Bentrosa & Ventrosa & Rcalcngo 88 & Conde de $A$ guilar \\
\hline Berzosa & Berzosa de Bureba & & \\
\hline Bilvestre & Vilviestre del l'inar & Señotio I. ${ }^{89}$ & Condestable de Castilla \\
\hline Billafrucla & Villafrucla & & \\
\hline Biniegra de Suso & Vinicgra de Abajo & Realengo $\%$ & Duque de Alba \\
\hline Biniegra de Yuso & Viniggra de Arriba & Realengo ${ }^{11}$ & Conde de Aguilar \\
\hline
\end{tabular}

84 Tenía dos alcaldes mayores nombrados por la villa $y$, al parecer, confirmados por el duque que conocían privativamente la primera instancia, y un alcalde de la fortaleza, nombrado por el duque, para conocer las apelaciones de los ordinarios. Cada tres años enviaba el señor un juez de residencia. Suyas eran las penas de cámara y las alcabalas. Del rey, el servicio real y la moneda forera (ibid., fols. 643-646).

85 También conde de Bañares.

86 La villa declara que se pertenecia porque «se compraron del rey nuestro señon. Los dos alcaldes ordinarios asi como el resto de los oficios de justicia los nombraba la villa de quien eran las penas de cámara. Las alcabalas, del rey (AGS-CC, fols. 357-358).

87 Tanto los dos alcaldes ordinarios como el alcalde mayor eran nombrados por el senoor de la villa. Esta se venía quejando de que, en contra de lo establecido por las leyes, los alcaldes ordinarios no eran renovados anualmente. Las penas de camara las llevaba el señor. Del rey eran las alcabalas y las tercias que se pagaban anualmente en Sigüenza (ibid., fols. $\left.419-423 \mathrm{v}^{\circ}\right)$.

8os alcaldes ordinarios nombrados por la villa ejercian la jurisdicción en nombre del rey. Los oficiales se tomaban cuentas unos a otros y al conde se le reservaba la posibilidad de hacerles residencia en los doce días siguientes a la conclusión de su oficio. Como señor se le pagaba la martiniega y la metindad. Del tey eran las alcabalas, tercias, penas de cámara y servicio real (ibid, fols. 466-469).

89 Los alcaldes ordinarios, nombrados por la propia villa, ejercían la jurisdicción civil y criminal en primera instancia a excepción de los tres casos: ofensa, sangte y mutilación de miembro, que los conocian conjuntamente con el gobernador de la Casa de Salas, puesto por el Condestable. Las penas de cámara aplicadas por los alcaldes ordinarios pertenecían a la villa. Las alcabalas al Condestable (ibid., fols. 283-284).

90 La villa nombraba a dos alcaldes ordinarios que ejercían la jurisdicción en nombre del rey. De él eran las alcabalas y las tercias. No se le pagaban el servicio real y las penas de cámara que, al parecer, eran de la villa por merced que el duque les tenia hecha por ser una tierra muy miserable (ibid., fols. $499-501 \mathrm{v}^{\circ}$ ).

91 La villa nombraba a sus alcaldes ordinarios y demás justicias que ejercían la jurisdicción 


\begin{tabular}{|c|c|c|c|}
\hline Bobadilla de Riotobia & Bobadilla & & \\
\hline Boçcguillas & Boccguillas & Scñorí C. ${ }^{92}$ & La villa \\
\hline Briçia, valle de & Bricia & & \\
\hline Brieba & Bricva de Cameros & Rcalcngo 93 & Conde de Aguilar \\
\hline Briones & Briones & & \\
\hline Brouia & Borobia & Señonío $L_{.}{ }^{94}$ & Carlos de Luna y Arcllano 95 \\
\hline Buelna, valle de & Buclna, valle de & & \\
\hline Burgo de Osma & Burgo de Osma, cl & & \\
\hline Busto & Busto de Burcba & & \\
\hline Caballar & Caballar & & \\
\hline Cabezon, valle de & Cabczón, valle dc & Realcngo ${ }^{96}$ & Rey \\
\hline Cabrejas del Pinar & Cabrejas del l'inar & Scñorío C. ${ }^{97}$ & La villa \\
\hline Cabuerniga, valle de & Cabuérniga, valie de & Realcngo ${ }^{9 B}$ & Rey \\
\hline Çacuar & Zazuar & & \\
\hline Cadinanos & Cardiñanos & & \\
\hline Calatanazor & Calatañazor & Señorío L. & Adelantado My. de Castilla \\
\hline
\end{tabular}

para pagar al merino que ponia la villa) y el servicio real. El conde, además de cobrar la martiniega y la merindad, tenía la posibilidad de tomar residencia a los oficiales en el plazo de los doce días siguientes a la conclusión de sus oficios (ibid., fols. 463-465).

92 La villa declara que se pertenece por haberse comprado al corregimiento de Sepúlveda (AGS-CC, 2767, fols. 61).

93 El Conde de Aguilar como titular del señorio tecibía ciertas prestaciones y rentas como, por ejemplo, la martiniega y la merindad. Sin embargo, no le pertenecía la jurisdicción que, en nombre del rey, ejercían los alcaldes ordinarios elegidos por la villa. El conde tenía detecho a tomarles residencia en los doce días siguientes a su salida del cargo. Del rey eran: alcabalas, tercias, penas de cámara y servicio real ( $A G S-C C, 2764$, fols. $470-472 \mathrm{v}^{\circ}$ ).

94 El señor era quien confirmaba a los alcaldes elegidos por la villa y nombraba al resto de las justicias, sin especificar (en adelante s.e.). Le pertenecian las penas de cámara, las tercias y las alcabalas (ibid, fols. 399-401).

95 Era el Mariscal de Castilla.

96 Cabezón y su valle pertenecian a la Corona real por sentencia y carta ejecutoria ganada al duque del Infantado, marqués de Santillana. Los concejos y lugares del valle acostumbraban a reunirse en Junta General. El rey enviaba al valle sus jueces de residencia que, con acuerdo de la Junta General, nombraban a los alcaldes ordinarios para oir y librar los pleitos. De la misma manera se nombra a dos regidores que conocían en apelación las causas civiles de cuantía inferior a diez mil mrs. (AGS-CC, 2764, fols. 538-542).

97 Esta villa pertenecía a la Mesa arzobispal de Osma. Hacía 14 o 15 años que el rey la vendió junto con otras villas, siendo la propia villa la que se compró al rey. Disfrutaba por ello de jurisdicción civil y criminal, alta y baja, mero y mixto imperio; jurisdicción que ejercía mediante dos alcaldes ordinarios nombrados por ella. De sus sentencias -dice la villa- se apelaba ante la Chancillería de Valladolid. Suyas eran las penas de cámara aplicadas para gastos de justicia, mientras que el resto de las imposiciones pertenecían al rey (ibid., fols. 303-305v').

98 El rey acostumbraba enviar al valle un juez de residencia que se encargaba de proveer a los alcaldes ordinarios. Algunos de los lugates de este valle - Bárcena mayor, Vraña, Selores y Ruente- pretendian eximirse de la jurisdicción real y ser vasallos de solariego del monasterio de

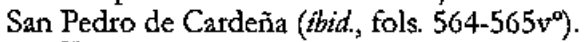

99 El señor de la villa, en este caso el adelantado de Castilla, nombraba a los dos alcaldes ordinarios que conocian las causas civiles y criminales de la villa y sus lugares, y a un alcalde mayor (ibid., fols. $303-305 \mathrm{v}^{\circ}$ ).

Hispania, LIX/2, nim. 202 (1999) 493-531 
Camargo la Mayor, valle de Camargo Camargo la Menor, valle de Camargo

\begin{tabular}{|c|c|c|c|}
\hline Canales & Canales de la Sierra & Realengo 100 & Conde de Aguilar \\
\hline Canicossa & Canicosa de la Sicrra & Scìorio I. 101 & Antonio Manrique de Iara \\
\hline Cañamares & Cañamares & & \\
\hline Caracena & Caracena & Scñorio l, 102 & luis Carcclo y l'oledo \\
\hline Carraton & Ccrmatón de Juarros & & \\
\hline Carricdo, valte de & Carricdo, valle de & & \\
\hline Cartes & Cartes & & \\
\hline Castañares de Yregua & Castañarcs de las Cucvas & & \\
\hline Castil de Peones & Castil de Peones & & \\
\hline Castilnovo & Castilnovo (condado de) & Señorío \. ${ }^{103}$ & Juana de Velasco y $A$ cagón \\
\hline Castillejo & Castillejo de Roblcdo & & \\
\hline Castrillo de la Reina & Castrillo de la Reina & & \\
\hline Castrojeriz & Castrojeriy & Scñorio J.. 104 & Conde de Castro \\
\hline Castroscrna de $\Lambda$ rriba & Castroserna de $\Lambda$ rriba & Señorio J ${ }^{105}$ & l'ctronila Durango \\
\hline Salcedo Castroserna de Avajo & Castroserna de $\Lambda$ bajo & Señorio $L_{.}{ }^{106}$ & Petronila Durango Salced \\
\hline
\end{tabular}

100 Éste es otro ejemplo, como ya se ha explicado, de señorío solariego. Su titular era el conde de Aguilar y, como tal, percibía algunas prestaciones señoriales como la martiniega y la merindad ( 1000 y $50 \mathrm{mrs}$. anuales respectivamente). La jurisdicción, que pertenecia al rey, era ejercida por los alcaldes nombrados por la villa. Al conde, como salvaguarda de su señorio, le quedaba tan sólo la posibilidad de realizar residencia en los días inmediatos a la conclusión de su oficio.d Del tey eran las alcalbalas, tercias, penas de cámata, así como el servicio real (ibid, fols. 486-488).

101 Esta villa había pertenecido a los abades de San Pedro de Arlanza hasta hacía unos treinta años, momento en el que el rey se la vendió, tal y como la poseian los abades, a Juan Manrique de Lara, del que fue sucesor el actual señor. Al parecer, la jurisdicción civil y criminal la ejercían, desde siempre, los alcaldes ordinarios de la villa -no se dice quién los nombra, probablemente la villa- a excepción de los casos de ofensa, sangre y mutilación de miembro, que pertenecen al señor. Es interesante observar que las alcabalas no eran ni al rey, ni del señor de la villa, sino del Condestable de Castilla (ibid, fols. 315-317).

102 Tanto los alcaldes ordinarios, que conocían en primera instancia, como el alcalde mayor, que lo hacía en primera y en apelación, eran nombrados por el señor. De él eran las penas de cámara, mientras que al rey se acudía con las alcabalas (ibid., fols. 288-290).

103 Esta villa y su tierra habían pertenecido al Condestable de Castilla hasta hacia menos de un año en que tómo posesión de ellas Juana de Velasco y Aragón. Ella era ahora quien nombra al alcalde ordinario y al alcalde y gobernador de la villa. Este último ejercia la jurisdicción en la villa y su tierra. Aunque entre todos no sumaban más de ochenta vecinos, el rey no tenía en ella nadia más que lo que toca de los millones (ibid., fols. $350-351 \mathrm{v}^{\circ}$ ).

104 El concejo de la villa nombraba a los alcaldes ordinatios que recibian la confirmación del conde. Éste ponía a su vez un alcalde mayor (ibid, fol. 264).

105 La villa y su tierra pertenecian a la villa de Sepúlveda, de la que fueron eximidas y tuego vendidas, junto con las alcabalas, al Dr. Gaspar Durango, alcalde de Corte (S. DI: Moxó, «La venta de alcabalas», pág. 505). La villa tenía dos alcaldes ordinarios elegidos y nombrados por Dĩa Petronila Durango Salcedo, actual señora de la villa, de entre las dobles candidaturas que se le presentaban. A ella le correspondía también nombrar al alcalde mayor. Del rey eran el servicio real, los millones y la moneda forera. De ella, las tercias, alcabalas, mostrencos, penas de cámara, escribanías y otros derechos (ibid., fols. 229-302).

106 Pertenecía a la jurisdicción de Castrosema de Arriba (ibidem).

Hihpania, LIX/2, nủm. 202 (1999) 493-531 


\begin{tabular}{|c|c|c|c|}
\hline Cavezon & Cabczón de la Sierra & Scroorio $]_{x} 107$ & Antonio Manrique de Jara \\
\hline Cayas de lorre & Tayas de Torre & & \\
\hline Cayas de Bascones & Tayas de Basconcs & & \\
\hline Coyon, valle de & Cayón, valle de & & \\
\hline Cerbera de Mguilar & Cervera del Río Nlhama & & \\
\hline C(re\%) & Cerczo de Riotirón & Scñorío ]. ${ }^{108}$ & Condestable de Castilla \\
\hline Ciadoncha & Ciadoncha & Senonio ]. 109 & lope l'crnảndez de Salazar 110 \\
\hline Çicça, valle de & Ciča, valle de & Señońo l. ${ }^{111}$ & Duçue del Infantado \\
\hline Cigudosn & Cigudosa & Scñorío ]. 112 & Conde de $A$ guilar \\
\hline Çilleruelo de $A$ bajo & Cillcruclo de $A$ bajo & & \\
\hline Ciria & Ciria & Señorío ]. 113 & Carlos de I una y Arclano \\
\hline Clauijo & Clavijo & & \\
\hline Castaneda, condado de & Castañeda & & \\
\hline Cobarrubias & Covarrubias & & \\
\hline Cornago & Cornago & Scĩorio ]. 114 & Alvaro de luna \\
\hline Corraquín & Zorraquin & & \\
\hline Coruña & Coruña del Condc & Scñorio ]. 115 & Conde de Coruña \\
\hline
\end{tabular}

107 Se trataba de un lugar pequeño, de pocos vecinos y negocios. Su concejo nombraba anualimente dos alcaldes mayores que necesitaban la confirmación del scinor o de su alcalde mayor que residía en la villa de San Leonardo. La villa explica que las peras de cámara eran del señor, pero que se las tomaba el rey "por quien esta de presente tomada posesion». Las tcrcias y las alcabalas no pertenecian ni al rey, ni al señor, sino al Condestable de Castilla (itid., fols. 325-327vo).

108 Los alcaldes ordinarios eran nombrados anualmente por la villa. El Condestable poría un corregidor. Se trata como hemos visto de una villa con numerosos lugares bajo su jurisdicción en diversas condiciones (ibid., fols. $636-640 \mathrm{v}^{\circ}$ ).

10\%) La villa nombraba a los alcaldes ordinarios que exan después confirmados por el senor. Éste ponia un alcalde mayor para las apelaciones aunque conocía también en primera instancia a prevención con los alcaldes ordinatios cuando residía en la villa. Alcabalas, tercias, moneda forera y pechos ordinararios, eran del rey (ibid, fols. $585-587 \mathrm{v}^{\circ}$ ).

110 Era vecino de Valladolid. Hacía treinta y tres años que se lo compró al duque de Bejar. La villa se quejaba de que se arrogaba más derechos de los que tenía su predecesor a base de irselos ganando mediante pleitos, y se cuestionaba seriamente si su título era suficiente (ibidem).

${ }_{111}$ Sólo se habla de un alcalde ordinario nombrado por el marqués de Cite y duque del Infantado. De éste eran las penas de cámara, alcabalas, moneda forera y otros tributos (ibid., fols. 560-563).

112 Se trataba de una población pequeña -unos cuarenta vecinos- que nombraban anualmente un alcalde ordinario y un alcalde de hermandad. El alcalde mayor lo ponía el señor de la villa, a quien pertenecian las penas de cámara (ibid., fols. $502-504 v^{\circ}$ ).

113 El Mariscal, Carlos de Luna y Axellano, nombraba a las justicias (s.e) y confirmaba a los alcaldes ordinatios. Suyas eran las alcabalas, las tercias y las penas de cámara (ibid., fols. 399-401).

114 Los alcaldes ordinarios eran propuestos por la villa y confirmados por el señor previa elección entre los que le presentaban. El aicalde mayor, que nombraba el señor, conocía las apelaciones y también la primera instancia a prevención con los alcaldes ordinatios. El señor percibín las penas de cámara y demás rentas que se pagaban en la villa, entre las que se encuentraban las alcabalas (ibid, fols. 554-555v ${ }^{\circ}$ ). De acuerdo a los datos aportados por S. DE Moxó, éstas le fueton vendidas a D. Pedro de Luna entre los años 1556 y 1559 («La venta de alcabalas", pág. 505).

115 Tanto los alcaldes ordinavios, que conocian en pimera instancia, como el alcalde mayor, que conocía la primera instancia a prevención con los anteriores y la apelación, eran nombrados por el señor del lugar, $A$ él le correspondian las penas de cámara y las alcabalas (AGS-CC, 2764, fols. 354-356).

Hi.pania, 1.IX/2, núm. 202 (1999) 493-531 


\begin{tabular}{|c|c|c|c|}
\hline Cozcurrita de Rriotiron & Cuzcurrita de Rio Tíón & & \\
\hline Cubillas de Çopena & Cubilla & & \\
\hline Deza & Deza & & \\
\hline Enciso & Enciso & & \\
\hline Entrena & Entrena & & \\
\hline Flandobiñes & Frandovinez & Señorio I. 116 & Dicgo Gonzälez de Mcdin \\
\hline Foncea y Arce & Foncea & Scõorío L. 117 & Duque del Infantado 118 \\
\hline Fresneda & Fresneda de la Sicrra Tirón & Scñorio L. ${ }^{119}$ & Condestable de Castilla \\
\hline \multicolumn{4}{|l|}{ Fresno de las Duenas } \\
\hline Frias, ciudad de & Frías & & \\
\hline Fuenmayor & Fucnmayor & & \\
\hline Fuentepinilla & Fuentepinilla & Scñorio C. ${ }^{120}$ & Conde de $\Lambda$ guilar \\
\hline Fuentealme;i & Fucntealmejii & & \\
\hline Fresaillo de las Duenas & Fresnillo de las Ducõas & Realcngo ${ }^{121}$ & Rey \\
\hline Fresno, junto a Carazena & Fresno de Caracena & Scñorío ] 122 & Marqués de Berlanga \\
\hline Fresno & Iresno (de Cantespino?) & Scñotio J. ${ }^{123}$ & Marqués de Villena \\
\hline Fuente junto a Santiestevan & Fuente & & \\
\hline Fuentealgemi & Fuentealgemil & & \\
\hline Fuentebureba & liuentebureba & & \\
\hline Fuentes, las & Fuentes de Magaña & & \\
\hline Fuentiduera & luentiducña & Señorio $1,{ }^{124}$ & Alvaro de Luna \\
\hline Galve & Galve de Sorbc? & & \\
\hline Gallincro & Gallinero & Realengo ${ }^{125}$ & García de Salazar \\
\hline
\end{tabular}

116 Un alcalde ordinario nombrado anualmente por la villa y confirmado por el señor, que conocía en primera instancia con el alcalde mayor puesto por el señor (ibid., fols. 257-260)

117 Los alcaldes ordinarios eran elegidos por la villa desde tiempo inmemorial. El señor ponía un gobernador que visitaba la villa (ibid., fols. $602-603 \mathrm{v}^{\circ}$ ).

118 Y marqués del Cañete.

119 La villa afirmaba que la jurisdicción le pertenecía aunque los alcaldes que nombraba necesitaran la confirmación del señor. De ella son las penas de cámara (ibid., fols. 459-462).

120 Dos alcaldes ordinarios nombrados por el procurador general de la villa, que conocían en primera instancia en todos los negocios y causas de la villa y su tierra. El conde nonbraba a un justicia mayor que conocía en primera instancia acumulativamente con los alcaldes ordinarios, además de las apelaciones de sus sentencias. La villa y su tierra tenia un total de 250 vecinos (ibid., fols. $455-458 \mathrm{vi}$ ).

121 Como hemos dejado ya anotado, esta villa no deberia haberse incluido en el listado por pertenecer en ese momento al corregimiento de Aranda de Duero. Su corregidor la visitaba dos veces por año, residiendo en ella cierto tiempo; conocía de todos sus pleytos en primera instancia y también, aunque suele negarseles esta atribución a los corregidores, en grado de apelación de los alcaldes ordinarios de la villa (ibid., fols. 306-30\% $\mathrm{v}^{\circ}$ ).

122 Su concejo nombraba dos alcaldes ordinarios que eran confirmados por el señor (íbid., fols. $\left.344-346 \mathrm{v}^{\circ}\right)$.

123 El concejo nombraba anualmente dos alcaldes ordinarios que eran confirmados por el marqués. Por encima de ellos estaba el gobernador del condado de Ayllón. Al marqués pertenecian todas las imposiciones a excepción del servicio real (ibid., fols. 224-225).

124 Hay un corregidor nombrado por el señor para la villa y su tierra. Sobre ella pretendía tener jurisdicción también el alcalde mayor del adelantamiento de Campos, por lo que la usó acumulativamente y a prevención con los del adelantamiento de Burgos (ibid, fols. 218-221).

$125 \mathrm{La}$ villa nombraba las justicias anualmente y ejercía la jurisdicción en nombre del rev. El señor no tenia ni alcalde mayor, ni mayordomo (ibid., fols. 385-389).

Hiphania, LIX/2, núm. 202 (1999) 493-531 
Torquemada?

\begin{tabular}{|c|c|c|c|}
\hline & & & \\
\hline Gama (y su valle) & Gama & Scñorio L. ${ }^{126}$ & Conde $\mathrm{de}$ Osorno \\
\hline Gomara & Gómara & Señonio C. ${ }^{127}$ & La villa \\
\hline Gormaz & Gormaz & Señorio L ${ }^{128}$ & Duque de Mendoza 129 \\
\hline Grañon & Grañón & & \\
\hline Grisaleña & Grisclaña & Señorio L. ${ }^{130}$ & Condestable de Castilla \\
\hline Gumiel de Mercado & Gumicl de Mercado & & \\
\hline Gumycl de Yzan & Gumiel de Hizán & & \\
\hline Haza & ІŁаza & Señorío L. ${ }^{131}$ & Conde de Miranda 132 \\
\hline Herce & Herce & & \\
\hline Huercanos & Hućrcanos & Señorio L. ${ }^{133}$ & Rey \\
\hline Jalón & Jalón de Cameros & & \\
\hline Jubera & Jubera & Señorío L. ${ }^{134}$ & Alvaro de Luna \\
\hline Junta de Juarr & & Señorio $C .{ }^{135}$ & Ciudad de Burgos \\
\hline
\end{tabular}

120 Tenía dos alcaldes ordinarios puestos por el conde que ejercian la jurisdicción en su nombre (ibid., fols. 572-575v').

127 Pertenecía al obispado de Osma. En 1570 fue incorporada a la Corona y vendida con su jurisdicción incluída a la villa. Los alcaldes ordinarios los nombraba la villa que percibía las penas de cámara (ibid, fols. $447-449 \mathrm{v}^{\circ}$ ).

128 El señor era quién nombraba a las justicias. Se habla de un alcalde y de un teniente de gobernador. El primero probablemente era el ordinario y, el segundo, el que conocía principalmente la apalación. Las alcabalas, tercias y penas de cámara pertenecian al duque (íbid, fols. 312-314).

129 Y conde de Castro.

130 Los alcaldes ordinarios los nombraba anualmente la villa y los confirmaba el Señor. Por carta ejecutoria las penas de cámara se las repartian el st. y la villa (ibid., fols. 568-569).

131 Los alcaldes ordinarios los nombraba el Conde quien ponia, además, un gobernador para la villa y su tierra (íbid., fols. 341-343).

132 A la sazón, presidente del Consejo Supremo de Italia.

$133 \mathrm{La}$ información que tenemos es confusa. Según Moxó -la misma que para Nestares y Lagunilla-, esta villa pasó a ser un señorio de nueva creación al ser desmembrada del Monastetio de Nájera («La venta de alcabalas», pág. 522). En su respuesta a Luján, Huércanos dice que pertenece a la Corona y al patrimonio real. En su jurisdicción parece estat bajo la de la ciudad de Nájera aunque, por ejecutoria real, los alcaldes ordinarios de Huércanos puedan conocer en primera instancia la materia criminal a prevención con los de Nájera. Las penas de cámara de las sentencias de sus alcaldes ordinarios son para el rey, mientras que las de las justicias de Nájera en primera instancia o en apelación ante su corregidor, se aplican para el duque de Nájeras. Las alcabalas pertenecian a la villa por compra que de ellas hizo al rey (ibid, fols. 616-618).

134 Los alcaldes ordinarios los nombraban el concejo y vecinos de la villa, mientras que al señor le pertenecía, desde hacía treinta años, el nombramiento de un alcalde mayor, que conocia las causas civiles y criminales a prevención con los ordinarios El concejo de la villa mantenía pleito ante la Chancillería de Valladolid para que se les restituyera a la situación anterior. Las tercias, alcabalas y servicio real, según el testimonio del propio concejo, los percibia el rey (AGSCC, 2764, fols. 611-615). Según datos aportados por Moxó, las alcabalas de esta villa fueron vendidas a Juan de Heredia ( $L$ La venta de alcabalas», págs. 521-522).

135 La ciudad de Burgos nombraba un corregidor para toda la jurisdicción de Juarros. A ella le pertenecían las penas de cámara y los mostrencos. Del rey eran las alcabalas, el servicio real, la moneda forera y ottos pechos; también parte de las tercias, que compartía con el Monasterio de Miraflores y el Hospital del Rey (AGS-CC, 2764, fols. 364-366).

Hipania, LIX/2, núrn. 202 (1999) 493-5.31 


\begin{tabular}{|c|c|c|c|}
\hline l_aguna & Iaguna de Cameros & & \\
\hline Jagunilla & Lagunilla de Jubera & Senorio I.. ${ }^{136}$ & Martin Rivera (?) \\
\hline langa y Oradero & Langa de Ducro & & \\
\hline l.antadilla & Iantadilla & & \\
\hline Jara & Lara de los Infantes & & \\
\hline \multicolumn{4}{|l|}{ Larraçona } \\
\hline Laraona & Jamona & & \\
\hline Jeça & Leza de Río Leza & Señorio J. 137 & Marcos Gucrero ${ }^{138}$ \\
\hline Lençes & Lences & & \\
\hline Lerma & lerma & Scñorio I. 139 & Marcués de Denia \\
\hline Leyba & Jeiva & Scñorío J. 140 & Sancho Mince de J cyva ${ }^{141}$ \\
\hline Llares, los & Llares, los & & \\
\hline Lloredo, alfoz de & Lloredo, alfoz dc & Realcngo 142 & Rey \\
\hline Lora, gentes de la & Lora, comarca dc & & \\
\hline Lumbreras & Iumbreras & & \\
\hline Macueca & Mazueza & & \\
\hline Maderuelo & Maderuclo & Scñorio L.. ${ }^{143}$ & Marqués de Villena \\
\hline Madrigal del Montc & Madrigal del Montc & Rcalengo(?) ${ }^{144}$ & Rey \\
\hline Madrigalcjo & Madrigalejo del Monte & & \\
\hline
\end{tabular}

136 Señorío de nueva creación desmembrado del Monasterio de Näjera. Sus alcabalas se vendieron a Baltasar de Lomellini, de quien las rescató la villa para ir al final a manos de Martín Rivera (S. DE Moxó, «La venta de alcabalas», pág. 522).

137 Al señor le pertenecía todo por título de venta que tenía del rey y ejercía la jurisdicción mediante un gobernador que nombraba al efecto. Las alcalbalas eran del rey, al igual que la moneda forera y el servicio real (AGS-CC, 2764, fols. 641-642v' ).

138 Consejero del rey, alcalde de su Corte y oidor de la Audiencia de Méjico.

130 Tenía dos alcaldes ordinarios, al parecer, nombrados por el marqués a quién pertenecían las alcalbalas, tercias, penas de cámara, infurciones y demás rentas; mientras que al rey le correspondian la moneda forera y el servicio real (ibid., fols. 570-571).

140 Los alcaldes ordinarios los nombraban entre la villa y el señor. Por encima estaba el gobernador de la Casa y Estado de Leiva nombrado por el señor. De él eran las penas de cámara, rentas y alcabalas. A esta villa acudían en grado de apelación algunos lugares del Estado (ibid., fols. 647-649).

141 Señor de la Casa y Estado de Leiva.

142 El valle del alfoz de Loredo y todos sus lugares fueron reducidos a la Corona real por sentencia y carta ejecutotia contra el duque del Infantado, marqués de Santillana. Se reunían en Junta General donde eligian a su alcalde ordinatio con acuerdo del rey. De la misma manera se nombraban dos regidores generales que conocian las apelaciones de las causas civiles de menor cuantia (hasta $10.000 \mathrm{mrs}$ ), (ibid., fols. 535-537).

143 Pertenecia al condado de Santibañez que tenía gobernador y juez mayor nombrado por el señor. Sus dos alcaldes ordinarios los nombraba anualmente el concejo de la villa y los confirmaba el marqués, que era quién nombraba al gobernador. Suyas eran las alcabalas y las penas de cámara (ibid., fols. 226-227).

144 No estoy segura de haber acertado en la clasificación. Sin duda, el titular de la villa era el rey que tenia en ella las alcabalas, tercias, pechos y servicio real, asi como la moneda forera los años que corresponden. Pero dudo en cuanto al titular de la jurisdicción, porque no sabemos realmente quien nombraba a los alcaldes ordinarios que ejercían la jurisdicción alta, baja, mexo y mixto imperio y que seran visitados por el Cabildo de la Iglesia Metropolitana de Burgos que es, además, quien recibe las penas de cámara (ibid., fols. 261-262).

Hippania, LIX/2, núm 202 (1999) 493-531 


\begin{tabular}{|c|c|c|c|}
\hline Magaña & Magaña & & \\
\hline Mahamud & Mahamud & & \\
\hline Mahauc & Mahave & & \\
\hline Mansilla & Mansilla & Realengo ${ }^{145}$ & Condc de Aguilar \\
\hline \multicolumn{4}{|l|}{ Matutc } \\
\hline Medina de Pumar & Mcdina de Pomar & Señorio L. ${ }^{146}$ & Condestable de Castilla \\
\hline Mcdrano & Mcdrano & & \\
\hline Melgar de I'ernanmental & Melgar de licrmental & & \\
\hline Meides & Micdes de Aticnza & Scñorio L. 147 & Marqués de Nmenara ${ }^{148}$ \\
\hline Mino & Villaldemiro & & \\
\hline Miranda del ]'itint & & Señorío I 1348 & Antonio Manrique de Lara \\
\hline Monasterio de Rodilla & Monastcrio de Rodilla & Scñorío L. ${ }^{150}$ & Condestablc de Castilla \\
\hline Moncalvillo & Moncalvillo & & \\
\hline \multicolumn{4}{|l|}{ Montalvo de Don Juarista } \\
\hline Montalvo & Montalvo, en Cameros & & \\
\hline Monte Agudo & Montcagudo de las Vicarias & Señorío J.. ${ }^{151}$ & Marqués de Almazán ${ }^{152}$ \\
\hline Monte Rubio & Monterrubio de Demanda & & \\
\hline Montcjo & $\begin{array}{c}\text { Montejo de la Vega de la/ } \\
\text { Scrrezuela }\end{array}$ & Señorio L. ${ }^{153}$ & Conde de Miranda \\
\hline
\end{tabular}

145 Los alcaldes ordinarios nombrados por la villa, ejercian la jurisdicción en nombre del rey, de quien eran las alcabalas, tercias, penas de cámara y servicio real. Al conde, como titular del señorío solariego, se le pagaba la martiniega y merindad, además tenía la posibilidad de tomar residencia a los ofciales en los doce dias siguientes a su salida del oficio (ibid., fols. 443-446).

146 R. SÁnciez Domingo, Las merindades de Castilla Vieja y su Junta General, Burgos, 1994, págs. 52,53 y 89 .

147 Los dos alcaldes ordinarios los confirmaba el señor tras elegirlos de entre los cuatro que nombraba la villa. El marqués nombraba un alcalde mayor que, con nombre de gobernador, conocía las apelaciones de los alcaldes ordinarios, además de visitar la tierra y hacer las residencias. Las imposiciones se hallaban ciertamente divididas. Al marqués le correspondían las penas de cámata y las alcabalas que fueron vendidas, en 1537, a Dria. Maria de la Cerda (S. DE Moxó, «La venta de alcabalas», p.496). El rey tan sólo percibía la moneda forere y el servicio real, mientras que el conde de Coruña, por merced que poseía de reyes anteriores, recibia las tercias (AGS-CC, 2764 , fols. $450-454 \mathrm{v}^{\circ}$ ).

148 Se trata del segundo marqués de Almenara, Diego de Mendoza.

149 Señotio de nueva creación, desmembrado del Monasterio de Arlanza en 1566, se vendió con las alcabalas a D. Juan Fernández Manrique de Lara (S. DE Moxó, «La venta de alcabalas», pág. 515).

150 El monasterio de Rodilla desde tiempo inmemorial pertenecía a la Casa y mayorazgo del Condestable de Castilla. No obstante, la villa tenía librada una ejecutoria en su favor por la que nombraba a sus alcaldes ordinarios que ejercian privativamente la jurisdicción en primera instancia. Nada se dice de la apelación que entendiendo estaría en manos de los oficiales del Condestable. Suyas eran las penas de cámara (AGS-CC, 2764, fols. 255-256 ${ }^{\circ}$ ).

151 Los dos alcaldes ordinarios eran nombrados por el señor tras elegir entre los cuatro que le presentaba la vilia. $\mathrm{Al}$ marqués pertenecían las penas de cámara, las tercias y alcalbalas, así como otros pechos (ibid., fols. $\left.396-398 \mathrm{v}^{\circ}\right)$.

152 Conde de Monteagudo.

153 Los dos alcaldes ordinarios, elegidos por el conde de entre los cuatro nombrados por el concejo, conocían la primera instancia a prevención con el alcalde mayor nombrado por el conde para conocer las apelaciones (ibid., fols. $396-398 \mathrm{v}^{\circ}$ ).

Hitpania, I,IX/2, núm. 202 (1999) 493-531 


\begin{tabular}{|c|c|c|c|}
\hline \multicolumn{4}{|l|}{ Montenegrillo } \\
\hline Montenegro & Montenegro de Cameros & Realengo ${ }^{154}$ & Conde de Aguilar \\
\hline Monterubio & Monterrubio de Demanda & & \\
\hline Moriana & Moriana & & \\
\hline Muño & & Señorio C ${ }^{155}$ & Ciudad de Burgos ${ }^{156}$ \\
\hline Murillo de Rioleza & Murillo de Rio Leza & & \\
\hline Muro de Cameros & Muro, en Cameros & & \\
\hline Muro de Estramusaguas & Muro de Aguas & & \\
\hline Nagera, ciudad de & Nágera & Scñorío L. & Duqque de Nájera \\
\hline Nalda & Nalda & & \\
\hline Navarrete & Navarrete & & \\
\hline Neila & Neila & Señorio C. ${ }^{157}$ & Condestable de Castilla \\
\hline Nestares & Nestares & Señorio L. ${ }^{158}$ & Martin de Rivera ${ }^{15 \%}$ \\
\hline Nieua & Nieva en Cameros & Señorio I. ${ }^{160}$ & Conde de Nieva ${ }^{161}$ \\
\hline Nobiercas & Noviercas & & \\
\hline Ocon & Ocón & & \\
\hline Ochanduri & Ochánduri & & \\
\hline Ojacastro & Ojacastro & Señorio $\mathrm{L}^{162}$ & Condestablc de Castilla \\
\hline Olmillos de Sasamon & Olmillos de Sasamón & & \\
\hline
\end{tabular}

154 Los alcaldes ordinatios nombrados por la villa ejercían la jurisdicción en nombre del rey. De él eran las alcabalas, tercias, penas de cámara y servicio real. Del conde, la martiniega y la merindad así como la posibilidad de tomar residencia a los oficiales en los doce dias siguientes a la conclusión de sus oficios (ibid., fols. 475-478).

155 La jurisdicción la ejercía la ciudad de Burgos mediante un alcalde mayor encargado, al tiempo, de visitar todos los lugates bajo su jurisdicción (ibid. fols. 236-239).

${ }_{156}$ Sobre la incorporación de Muño y sus cinco aldeas a la ciudad burgalesa véase J. A. BONACHí, E/ señorio de Burgos durante la Baja Edad Media (1255-7508), págs. 61 y sigs.

157 La villa nombraba, sin necesidad de postrera confirmación, a sus dos alcaldes mayores que ejercían la jurisdicción civil y criminal, mero y mixto imperio en nombre de la propia villa. A su concejo pertenecían las penas de cámara; al rey, el servicio real y la-moneda forera y al Condestable, las alcabalas y las tercias (AGS-CC, 2764, fols. $496-498 \mathrm{v}^{\circ}$ ).

158 Esta villa fue desmembrada del Monasterio de Nájera. Nombraba dos alcaldes ordinatios que conocían en primera instancia a prevención con el alcalde mayor, juez de apelación puesto por el señor. De él eran las penas de cámara, mientras que las alcalbalas pertenecían a la villa por compra que de ellas se hizo al rey (ibid., fols. 434-436). Estos datos no concuerdan exactamente con los aportados por Moxó, según los cuales, en 1590 se vendieron las alcabalas a Baltasar Lomellini, de quien las rescata la villa para pasar, después, a Martín de Rivera, que es el que figura como señor de la villa en 1598 ("La venta de alcabalas", pág. 522).

159) Se trata de un vecino de la villa de Usagre que compró la villa hacia 1581.

160 La villa nombraba un alcalde ordinario para la primera instancia. El conde, un alcalde mayor para conocer las apelaciones de la villa y sus aldeas. Éste tomaba a su vez la residencia del alcalde ordinario y de los demás oficiales. Al conde de Zúñiga pertenecían las penas de cámara y las alcabalas (AGS-CC, 2764 , fols. $440-442 \mathrm{v}^{\circ}$ ).

161 D. Antonio de Velasco y Zúñiga (ibidem).

162 Los ocho o diez lugares, que etan en realidad caseríos y cabañas situadas en el monte y en tierras ásperas, formaban un sólo concejo, un ayuntamiento. Nombraban a sus dos alcaldes mayores que necesitaban la confirmación del Condestable. A él pertenecian las panas de Cámara (ibid., fols. $\left.599-601 v^{9}\right)$.

Hispania, LIX/2, núrn 202 (1999) 493-531 


\begin{tabular}{|c|c|c|c|}
\hline Ontoria de la Cantera & Hontoria de la Cantera & Señorio C. 163 & I.a villa \\
\hline Ontoria de Baldarados & Hontoria dc Valdcarados & Behctria 164 & Rey \\
\hline Ontoria del Pinar & Hontoria del Pinar & Scñorio L. 1115 & Antonio Manrique de Lara \\
\hline Oña & Oña & & \\
\hline Oquillas & Oquillas & Señorio L, ${ }^{166}$ & Duque de Osuna \\
\hline Ormaças, las & Hormazas, las & & \\
\hline Ornillos del Camino & I-Iornillos del Camino & & \\
\hline Ortigosa & Ortigosa & Señorío L. ${ }^{167}$ & Duque dic Nájera \\
\hline Osma, ciudad de & Ciudad de Osma & Señorío $L^{168}$ & Marqués de Berlanga 169 \\
\hline Oz de $A$ rreba, valle de & Hoz de Arreba & & \\
\hline Padilla de Arriba & Padilla de Arriba & & \\
\hline Padilla de $\Lambda$ vajo & Padilla de $\Lambda$ bajo & & \\
\hline Palacios de la Sierra & Palacios de la Sierra & Señorío L. ${ }^{170}$ & Condestable dc Castilla \\
\hline Palacuelo & Palpzuclos de Muño & & \\
\hline Panpliega & Pampliega & & \\
\hline Pedraça de la Sierra & Pedraza & & \\
\hline Pedrosso & Pedroso & Realengo ${ }^{171}$ & $\mathrm{M}^{\circ}$ Sta. $\mathrm{M}^{2}$ la Real de Näjera \\
\hline
\end{tabular}

163 La villa pertenecía a Gómez Manrique de Mendoza y a su mujer, Isabel de Velasco, condes de Castrojenz. El 5 de mayo de 1568, la villa compró su jurisdicción y tomó posesión el día 13 de ese mismo mes. Los alcaldes ordinarios los nombraba el concejo de la villa y ejercía la jurisdicción alta, baja, mero y mixto imperio. En la escritura de venta se establecia, entre otras cosas, que las penas de cámata serían del concejo y vecinos de la villa, pero de momento las venía cobtando el rey por no haberse negociado con él rey y su Consejo este particular Las alcabalas también pertenecian al rey, mientras que es el Monasterio de Miraflores quien se llevaba las tercias (ibid., fols. 320-321v").

164 Era behetría de mar a mar y pertenecía a la Corona real. Los alcaldes ordinarios los nombraba la villa y ejercian la jurisdicción civil y criminal, mero y mixto imperio por privilegio y antigua costumbre. Del rey eran las alcabalas, tercias, servicio real y penas de cámara (ibid., fols. 338-340).

165 Señotio de nueva creación, desmembrado del Monasterio de Arlanza en 1566 que se vendió a D. Juan Fernández Mantique de Lara (S. DE Moxó, (La venta de alcabalas), p. 515). El concejo nombraba anualmente dos alcaldes ordinarios que habian de ser confirmados por el señor. Conocían en primera instancia las causas civiles y criminales y si estaba el alcalde mayor nombrado por el señor lo hacían a prevención. Dicho alcalde mayor residía en la villa de San Leonatdo, conocía las apelaciones, tomaba cuentas y hacía las residencias. Al señor pertenecían las alcabalas, tercias y penas de cámara (AGS-CC, 2764 , fols. $347-349 \mathrm{v}^{\circ}$ ).

166 Sus alcaldes ordinarios eran nombrados por la villa y confirmados por el señor, de quien eran las penas de cámara (ibid., fols. $333-334 \mathrm{v}^{\circ}$ ).

167 Los alcaldes ordinarios eran nombrados por el señor al igual que el alcalde mayor que residía en la villa de Nájera. Suyas eran las penas de cámara (ibid., fols. 424-427).

168 El marqués tenía en la villa un gobernadox que era quien administraba la jurisdicción alta y baja. Del matqués eran las alcabalas y las penas de cámara (íbid., fols. $318-31 \mathrm{v}^{\circ}$ ).

169 D. Pedro Martínez de Tobar (ibidem).

170 La jurisdicción alta y baja, mero y mixto imperio era desde tiempo inmenorial de la villa, que la ejercía mediante los dos alcaldes ordinarios que anualmente nombraba al efecto. El señor ponia un gobernador que era el de la Casa de Salas, conocía las apelaciones y tomaba residencia cada cuatro años. Al Condestable corresponden las alcabalas, tercias y la mitad de las penas de cámara; la otra mitad pertenecian al concejo de la villa (ibid., fols. $328-329 \mathrm{v}^{\circ}$ ).

171 El alcalde ordinazio era elegido anualmente por la villa y ejercía la jurisdicción en nombre del rey, de quien eran las alcabalas, tercias, penas de cámara y servicio real. El Monasterio visitaba la villa anualmente y recibía 9 ducados y el yantar (íbid., fols. 479-482). 


\begin{tabular}{|c|c|c|c|}
\hline Jenagos, valle de & l'enagos & & \\
\hline Penaranda & Peñaranda de Ducro & & \\
\hline Peones & Pcones & & \\
\hline Peral, cl & lecal de $\Lambda$ tlan:a & Scãorio ] 172 & Juan Curiel de la Torre \\
\hline Pesadas & Pesadas & & \\
\hline P'esquera & Pesquera & & \\
\hline Piclagos & Pićlagos & & \\
\hline Pie de Conclua & l'ic de Concha & & \\
\hline Pinillos & vinillos & & \\
\hline Poca & Poza de Ja Sa] & Señorío ], 173 & Marqués de loza \\
\hline Preçienço & Presencio & & \\
\hline l'rcjano & Préjano & & \\
\hline l'uebla de Argançon, la & Pucbla de Arganzón, la & Señorio l. 174 & Condestable de Castilla \\
\hline Qucl & Quel & Senorío L. 175 & J. de la Mota y D. de Sante \\
\hline Quintanar dc la Sicrra & Quintanar de la sicrra & Señorio ] 176 & Pedro Neyla \\
\hline Rave & Rabé de las Calzadas & & \\
\hline Ravanera & Rabanera & Scñorío ] 177 & Antonio Manrique de Jara \\
\hline Redecilla & Redecilla del Camino & & \\
\hline
\end{tabular}

172 Se trata de un señotio de nueva creación desmembrado del realengo en 1575 . Pertenecía a la villa de Melgar y se vendió junto con sus alcabalas a D. Juan Curiel de la Torre, asentista que participó junto a los más importantes banqueros genoveses en las negociaciones levadas a cabo para superar la crisis económica de aquellos años (S. DE Moxó, «La venta de alcabalas", págs. 517-518 y 527).

$173 \mathrm{El}$ marqués nombraba a los alcaldes ordinarios y percibía las penas de cámara. El rey poseía minas y salinas en sus términos (AGS-CC, 2764, fols. 233-234).

174 Siruada en el Condado de Treviño, pertenecía al Condestable de Castilla quien nombraba a sus dos alcaldes ordinarios. De él eran las penas de cámara y las alcabalas (ibid, fols. 520-523).

175 Ambos eran señores de la villa. En un momento determinado se envió a un oidor de la Audiencia de Valladolid para solventar las diferencias existentes entre ellos. El oidor dividió la villa en dos: Quel de Yuso para Juan de la Mota y Quel de Suso para Diego de Sante. A tal fin se sirvió del rio que atravesaba la villa. Cada una de las partes tenia sus propios alcaldes ordinarios para el conocimiento de la primera instancia y cada señor nombraba un alcalde mayor que en su parte conocia la primera instancia a prevención con los ordinarios y la apelación siempre que no hubiera conocido en primera instancia. Cada uno recibía las penas de cámara que le correspondian. Del rey era el servicio real y la moneda forera. Por último, las alcabalas pertenecían todas de Juan de la Mota (ibid., fols. 628-635), fueron vendidas a su antecesor Pedro Díaz de la Mota en 1547 (S. DE Moxó, «La venta de alcabalas", p.499).

176 Pedro Neila se la compró a Juan Asenjo. La jurisdicción pertenecía a la villa a excepción de los tres casos de ofensa, sangre y mutilación de miembro, casos reservados siempre al señor. Las penas de cámara le pertenecían (AGS-CC, 2764, fols. 280-282)

177 Rabanera era una villa de unos treinta y cuatro vecinos, todos hombres que andaban en carreterias. Pertenecía al Monasterio de Arlanza pero fue vendida con sus alcabalas en 1556 a D. Juan Femández Manrique de Lara (S. De Moxó, «La venta de alcabalas», pág. 515). En la actualidad, por motivos que desconocemos, se hayaba secuestrada por el rey. Los alcaldes ordinarios eran nombrados por la villa sin necesitar una posterior confirmación por parte del señor. Ejercian en primera instancia la jurisdicción civil y criminal y del concejo eran las penas de cámara por costumbre inmemorial. Mientras que al señor le correspondian las alcabalas y las tercias (AGS-CC, 2764, fols. 372-374).

Hipponits LIX/2, núm. 202 (1999) 493-531 


\begin{tabular}{|c|c|c|c|}
\hline Rcoçin, valle de & Reocin, valle de & Señotío J. ${ }^{178}$ & Duque del Infantado \\
\hline Retortillo & Retortillo de Soria & Señotio l.. ${ }^{179}$ & Juan 'lorres de Mendoza \\
\hline Revilla Vallcjera & Revilla-Valicjcra & Bchetría 180 & Rey \\
\hline Riaça de la Sictra & Riaza & Señorío I., ${ }^{181}$ & Duque de Maçueda \\
\hline Rivafrecha & :Ribafrecha & & \\
\hline Robics & Robres del Castillo & & \\
\hline Rravuancra & Rabancra del l'inar & & \\
\hline Rregumicl & Regumiel de la Sicrra & & \\
\hline Rrcjas & Rejas de San Esteban & & \\
\hline Rucabado & Riocavado de la Sicrra & & \\
\hline Rucsga y su vallc & Valle de Ruesga & Scrioría l, ${ }^{182}$ & $\begin{array}{r}\text { Condestable de Castilla y } \\
\text { de Jeón. } 183\end{array}$ \\
\hline $\begin{array}{l}\text { Runansa y Val de San/ } \\
\text { Viccnte }\end{array}$ & $\begin{array}{l}\text { Rionansa y Val de San/ } \\
\text { Vicente }\end{array}$ & & \\
\hline Sagnetes de la Lora & Sargentes de Jora & & \\
\hline Sagramenia & Sacramenia & & \\
\hline Salacar de $\Lambda$ maya & Salazar de Amaya & Scĩorio L. ${ }^{184}$ & Bernardino de Velasco. ${ }^{185}$ \\
\hline Salarona & Solarana & & \\
\hline Salas de los Ynfantes & Salas de los Infantes & & \\
\hline San Iconardo & San Lonardc dc Yagüc & Señorío I.. ${ }^{186}$ & Antonio Manrique de Lara \\
\hline San Pedro dc Yanguas & $\begin{array}{c}\text { San Pedro de Yanguas de/ } \\
\text { liresma }\end{array}$ & & \\
\hline San Millan de Laxa & & & \\
\hline $\begin{array}{l}\text { San Vicente } \\
\text { Sanrroman }\end{array}$ & $\begin{array}{l}\text { San Vicente de Lcón } \\
\text { San Román de Cameros }\end{array}$ & Scñorío $1 . .{ }^{187}$ & Conde de $\Lambda$ guilar \\
\hline
\end{tabular}

178 Ibid., fols. 543-545.

179 Los alcaldes ordinazios, nombrados anualmente por el concejo, etan confirmados por el señor. Suyas eran las penas de cámara (ibid., fols. 269-271v').

180 Se trata de un lugar de behetría patrimonio del rey. La villa nombraba los alcaldes ordinatios que, por merced que tiene del rey, podían juzgar en lo civil hasta $400 \mathrm{mrs}$. En materia criminal, tan sólo recibían información y hacian prisiones, después tenian que remitir los casos a la villa de Castrojeriz que era del Conde de Castro y en el que éste tenía un alcalde mayor. Las alcabalas y tercias eran del rey (ibid., fols. $263-265 \mathrm{v}^{\circ}$ ).

${ }_{181}$ Al parecer, esta villa era de la Iglesia Mayor de Segovia y fue vendida con su jurisdicción y alcabalas al duque de Maqueda (ibid., fols. 597-598v').

182 Todas las justicias del valle eran nombradas por el Condestable. Entre ellas destaca el cotregidor y su teniente. Del Condestable eran las penas de cámara (ibid., fols. 517-519).

183 D. Juan Fernández de Velasco (ibidem).

184 La villa nombraba anualmente dos alcaldes ordinarios que ejercían la jurisdicción en primera instancia de forma privativa por privilegio. La apelación la conocia el alcalde mayor que para ello nombraba el señox. Este percibía las penas de cámara, mientras que las alcabalas que pertenecian al rey se pagaban, sin embargo, con libranza del rey al Condestable de Castilla (ibid., fols. 240-243).

185 Era Veedor general de la gente de guerra (ibid., fols. 240-243).

186 Lugar desmenbrado del Monasterio de Arlanza y vendido en 1566, junto con sus alcabalas, a D. Juan Fernández Manrique de Lara, Clavero de Santiago y consejero del rey (S. DE Moxó, «La venta de alcabalas», p. 515).

187 La villa nombraba y el señor confirmaba anualmente dos alcaldes ordinarios: uno, el de los hijosdaigo, el otro, el de los buenos hombre. Ambos conocían privativamente la primera instancia. Se silencia el nombramiento de un alcalde mayor para la apelación. Las alcabalas las percibia el rey (AGS-CC, 2764, fols. 491-495).

Hipania, LIX/2, núm 202 (1999) 493-531 


\begin{tabular}{|c|c|c|c|}
\hline Santa Cruz de Yanguas? & Santa Cruz de Yanguas & & \\
\hline Santa Cru\% del Valle & Santa Cruz del Valle & Scñorio $\mathrm{J}_{\text {, }}{ }^{88}$ & Pcdro de Vclasco y Rojas \\
\hline Santa Gadea & Santa Gadea del Cid & & \\
\hline Santa Gadea de Campoo & Santa Gadea & Scrnorio J. 18") & Marqués de $A$ guilar \\
\hline Santa Maria de las Ollas & & Señorío L $1 \% 0$ & Antonio Manrique de Iara \\
\hline Santa Maria del Campo & Santa Maria del Campo & & \\
\hline Santibanez de Valdesgueva & & Scñorío L. ${ }^{191}$ & Pctronila Durango Salcedo \\
\hline Santiestevan de Gozmar & San Estcban de Gozmar & & \\
\hline $\begin{array}{l}\text { Santillana } \\
\text { Santo Asensio }\end{array}$ & Santillana & Scñorío L. ${ }^{192}$ & Duque del Infantado \\
\hline Santo Domingo de Silos & Santo Domingo de Silos & & \\
\hline Santo Vizente de la Sonsier & & San Vicente do & la Sor \\
\hline Santoña y su puerto de & Santoña & Señorío C. ${ }^{193}$ & Rey \\
\hline Santoyo & Santoyo & & \\
\hline Sasamon & Sasamón & & \\
\hline Scalante & Escalante & & \\
\hline Sedano, villa y valle de & Sedano y su valle & Scñorio J. ${ }^{194}$ & $\begin{array}{c}\text { Marqués de Aguilar de/ } \\
\text { Campoo }\end{array}$ \\
\hline Seron & Serón de N & Señorio L. ${ }^{195}$ & Marqqués del Pozo \\
\hline Soba, valle de & Soba, valle de & Señonio L. ${ }^{16 n}$. & Condestable de Castilla \\
\hline
\end{tabular}

${ }_{188}$ El señorío y la jurisdicción alta, baja, mero y mixto imperio de Santa Cruz del Valle Urbión pertenecia a D. Pedro de Velasco por venta que le hicieron el rey y el Condestable de Castilla. Los alcaldes ordinarios eran nombrados por el señor. Suyas eran las tercias y alcabalas, además de las penas de cámara. Del rey, el servicio real y la moneda forera (íbid., fols. 489$490 \mathrm{v}^{\circ}$ ).

189 Se trata del alfoz de Santa Gadea de Campoo. Elegía anualmente un alcalde ordinario que confirmaba el marqués. De él eran las alcabalas y demás pechos, derechos y merindades (ibid, fols. 557-559).

190 La villa nombraba dos alcaldes ordinarios que necesitaban la confirmación del señor. Éste nombraba al tiempo un teniente de alcalde mayor para la apelación. Se dice que el rey no percibía nada porque de D. Antonio Manrique de Lara eran alcabalas, tercias y moneda forera (ibid., fols. $286-287 \mathrm{v}^{\circ}$ ).

191 Dña. Petronila elegía dos alcaldes ordinarios de los cuatro presentados por la villa (ibid., fols. 330-3320 $\mathrm{v}^{\circ}$ )

192 Ibid., fols. $543-545$.

193 Esta villa se eximió del señorio y vasallaje del Monasterio de Santa María la Real de Näjera y se incorporó a la Corona a cambio de cierta cantidad. La villa nombraba anualmente a sus alcaldes ordinarios y cobraba las penas de cámara al comprarselas al rey cuando se redimió de la jurisdicción del Monasterio. Pagaban, además, cierta cantidas a la reina y al Condestable de Castilla por los derechos de alcabala (ibid, fols. 766-567v').

194 Pertenecía al marqués de Aguilar de Campoo. En 1582 compró al rey sus alcabalas (S. DE Moxó, «Ĺa venta đe alcabalas», p. 519).

195 Tanto los dos alcaldes ordinatios, como el alcalde mayor eran nombrados por el señor. A él pertenecen las penas de cámara, mientras que el rey recibía el servicio real y la moneda forera. Nada se dice de las alcabalas (AGS-CC, 2764, fols. 402-406).

196 Los distintos lugates del valle se reunían en Junta General compuesta por un procurador general, los diputados y regidores. Los jueces ordinatios del valle, así como el corregidor y su teriente, eran nombrados por el Condestable. De él eran las penas de Cámara, y aunque nada dicen de las alcabalas, se hace hincapié en que el rey no tenia nada en el valle (ibid., fols. 546-549).

Hispania, LIX/2, núm. 202 (1999) 493-531 


\begin{tabular}{|c|c|c|c|}
\hline Sojucla & Sojuela & Sciòorío L. ${ }^{197}$ & Diego de Medrano Menor \\
\hline Soncillo (y valle de & & & \\
\hline Valdevezana) & Suncillo & Scñorio J. 198 & Juan dc Porras \\
\hline Soto & Soto en Cameros & Señorio L ${ }^{199}$ & $\begin{array}{l}\text { J. de Mendoza y / } \\
\text { J. de Castejón }\end{array}$ \\
\hline Sotopalacios & Sotopalacios & Scñorio 1.200 & Adelantado My. de Castilla \\
\hline Sotosaluos & Sotosalbos & Señorío J 201 & Pedro de Zúãiga \\
\hline Spinilla & Espinilla & & \\
\hline Spinosa de los Monteros & Espinosos de los Monteros & & \\
\hline Spinosilla & Espinosilla de San Bartolomé & & \\
\hline Sturcie & Santurde & & \\
\hline Sturdejo & Santurdejo & & \\
\hline Suellacabras & Sucllacabras & Señorío I. 202 & Duque de Alba \\
\hline Tardaxos & Tardajos & Realengo 203 & Rey \\
\hline Texada & Tcjada & & \\
\hline Toranço, valie de & Toranzo, valle de & & \\
\hline Tordepadre & Torrepadre & & \\
\hline Torre & 'Iorre en Cameros & & \\
\hline Torrecilla de los Cameros & Torrecilla en Cameros & & \\
\hline
\end{tabular}

197 Los alcaldes ordinarios eran nombrados anualmente por la villa y conocían todos los casos civiles y criminales que se daban en la villa y su jurisdicción. A ella le pertenecen las alca" balas por compra que de ellas hizo al rey. El señor de la villa, a quien correspondían las penas de cámara, nombraba un alcalde mayor que conocia acumulativamente y a prevención con los alcaldes ordinarios la primera instancia; le correspondía también la apelación de los alcaldes ordinarios. Sojuela, villa de unos 60 vecinos, era administrada en nombre de su señor por Francisco Fernándes vecino de la ciudad de Navarrete (ibid., fols. 619-622v" $)$.

198 El señor ponía un gobernador y nombraba a la justicia ordinaria del valle. De él eran las penas de cámara, mientras que el rey percibia las alcabalas, pechos y servicio real (ábid., fols. 533-534).

199 El señotío de esta villa se encontraba dividido en cinco partes, cuatto pertenecían a Juan de Mendoza, mientras que la quinta eta de su cuñado J. de Castejón, marido de Catalina de Mendoza. Los alcaldes ordinarios los nombraba anualmente la villa, mientras que los señores, turnándose por años, nombraban un alçalde ordinario que conocía la primera instancia acumulativamente y a prevención con los alcaldes ordinarios, también la apelación. Las penas de cámara se repartia, conforme a una ejecutoria entre los dos señores (ibid., fols. 604606 $\mathrm{v}^{\circ}$ ).

200 Sotopalacios era la villa cabeza de la jurisdicción y merindad de Río de Ubiema, algunos de cuyos lugares eran del Monasterio de Nuestra Señora de Rioseco. Aunque los testigos comienzan afirmando que tanto la villa como sus lugares pertenecen a la jurisdicción del rey, a continuación, dirán que todas las justicias y merinos del valle, asi como el alcalde mayor y a su teniente eran nombrados por el Adelantado Mayor de Castilla, que percibía las penas de cámara. Al rey pertenecían las alcabalas, tercias, moneda forera y otros derechos (ibid., fols. 576$\left.581 v^{\circ}\right)$.

201 Lugar secularizado de la Dignidad Arzobispal de Segovia. Las alcalbalas pertenecian al señor por enajenación en 1538 (S. DE Moxó, «La venta de alcabalas», p. 496).

202 Se trata de una villa pequeña con dos lugates que no sumaban más de doce vecinos. Al alcalde ordinario lo nombraba el duque, que tecibía las penas de cámara. El rey tenía el servicio real y la moneda forera (AGS-CC, 2764, fols. 505-508).

203 La villa era quien nombraba anualmente a los dos alcaldes ordinarios, también a tres merinos para ejercer la jurisdicción real. Las penas de cámara eran del rey (ibid., fols. 244-247). 


\begin{tabular}{|c|c|c|c|}
\hline Toremuña & Torremuĩa & Scñorio Ii. 204 & $\begin{array}{r}\text { Convento de Sta. } \mathrm{M}^{\mathrm{a}} \mathrm{de} \text { la/ } \\
\text { Villa de II Ierec }\end{array}$ \\
\hline 'lovar & Tobar & & \\
\hline Touia & 'Tobia & & \\
\hline Trebiño & Treviño & & \\
\hline St. Millan, villa y valle & Valle de San Millán & & \\
\hline I'repeana & Ircviana & & \\
\hline Trcucjano & Trevijano & Señorio $L^{205}$ & Marcos Gucrrero \\
\hline Tudela, valle de & Tudela & & \\
\hline lurucgano & 'lurćgano & & \\
\hline 'luvilla de lago & 'Tubitla del L_ago & & \\
\hline Utrilla & Utrilla & Scñorio l. 206 & Duque de Medinaceli \\
\hline Val de San Vizentc & San Vicente del Valle & Scĩorío l. 207 & Condestable de Castilla \\
\hline Valdcarados, valle de & Valdearados, valle de & & \\
\hline Valdelucio, valle de & Valdelucio, valle de 208 & & \\
\hline Vega, la & 'Torrclavega & & \\
\hline Verlanga & Berlanga de Ducro & Scriorio l. $20 \%$ & Marcués de Bcrlanga \\
\hline \multicolumn{4}{|l|}{ Vezindad, valle de? } \\
\hline Vilvestre? & Vilvictetre del linar & & \\
\hline Villa Copeque & Villazopeque & & \\
\hline Villa Ximcno & Villajimeno & & \\
\hline Villabclayo & Villavclayo & Realcruoro 210 & Conde de Aruilar \\
\hline
\end{tabular}

204 La jurisdicción civil y criminal de la villa y su tierra la ejercia un alcalde mayor nombrado anualmente por la villa, de él se podía apelar ante la abadesa o en donde al apelante más le conviniera. Del convento eran las penas de cámara, mientras que al rey pertenecía las aĺcabalas, el servicio ordinario y la monada forern (ibid., fols. 428-433).

205 La villa y su jurisdicción pertenecian a $M$. Guerrero por venta que le hizo el rey. El senor nombraba un gobernador que era quien ejercía, junto a sus tenientes, la jurisdicción. Suyas eran las penas de camara. Del rey, las alcabalas, la moneda forera y otros derechos (ibid., fols. $\left.626-627 \mathrm{v}^{\circ}\right)$.

200 Pertenecia a la Dignidad arzobispal de Toledo de la que fue desgajada y vendida al duque de Medinaceli en tomo a 1575. El duque nombraba al gobernador de la villa que ejercia la jurisdicción en ella; éste, a su vez, nombraba un teniente que era quien realmente la ejercia. En la actualidad, la villa señalaba un número de oficios (dos alcaldes de hermandad, cuatro regidores, dos procuradores, un merino, etc) de entre los que el duque eligia a un alcalde ordinario, dos regidores, etc. Sobre este extremo la villa mantenía un pleito en la Chancilleria puesto que antes, a excepción del gobernador, era ella quien nombraba todos los oficios. El duque percibía las penas de cámara, las tercias y las alcabalas, estas últimas, conseguidas en 1591 como pago de unas Salinas. (ibid., fols. 407-411 y Moxó, «La venta de alcabalas», pág. 523).

$207 \mathrm{El}$ valle nombraba tres alcalde ordinarios que sin necesidad de ser confirmados por el Condestable ejercían la jurisdicción en él. Al Condestable pertenecían las penas de Cámara y las alcabalas (ibid., fols. $473-474 \mathrm{v}^{\circ}$ )

208 Al parecer el Valle no tenía jurisdicción, sino que estaba dividido en tres barrios sujetos en lo civil y en lo criminal a la jurisdicción de la villa de Villadiego (ibid., fols. 231-232).

209 La jurisdicción la ejetcía el marqués a través de un corregidor que conocia en primera instancia, y de un alcalde mayor al que correspondian las apelaciones de las sentencias así como los autos del corregidor (ibid., fols. 291-294v $\mathrm{v}^{\circ}$ ).

210 Los alcaldes ordinarios los nombraba la villa y ejercian la jurisdicción en nombre del rey. De él eran las alcabalas y las tercias, las penas de cámara y el servicio real. Al conde, como

Hipania, J.IX/2, núm. 202 (1999) 493-531 


\begin{tabular}{|c|c|c|c|}
\hline Villadcpun & Castildelgado & Señorio I. 211 & Francisco Dclgado \\
\hline Villadicgo & Villadicgo & Scñorio $\mathrm{L}^{212}$ & Condertable de Castilla y l cón \\
\hline Villacscusa & Villacscusa & & \\
\hline Villafranca de Montes de Oca & Villafranca-Montes de Oca & Rualengo 213 & Irey \\
\hline $\begin{array}{l}\text { Villaho: } \\
\text { Villalaço }\end{array}$ & Villahoz & & \\
\hline Villalva de Losa & Villalva de Iosa & Scñorí C. 214 & Condestable de Castilla \\
\hline Villamayor de los Montes & Villamayor de los Montes & & \\
\hline Villanucua de los Camcros & Villanucva de los Cameros & Scñorio C. 215 & Conde de Aguilar \\
\hline Villaquiran & Villaquirán & & \\
\hline Villasana & Villasana de Mena & & \\
\hline Villasandigero & & & \\
\hline Vullasidro & Villasidro & & \\
\hline Villavcrdc, valle dc & Villaverde & & \\
\hline Villoria & Villoria de Rioja & Scriorio l. 216 & Ruy Diaz de Vcrgara \\
\hline Viiloslada & Villoslada de Cameros & Scñorio J 217 & Duque de Nájera \\
\hline Viruiesca & Brivicsca & & \\
\hline Voço & Во०\% & & \\
\hline Yanguas & Yanguas & & \\
\hline Yglessias & Iglesias & Bchetría 218 & Rey \\
\hline Yguñal & & & \\
\hline
\end{tabular}

señor de la villa, se le pagaba la martiniega y la merindad; tenía además la posibilidad de residenciar a los oficiales de ja villa en los doce dias siguientes a la conclusión del oficio (ibid., fois. 483-485).

211 Pertenecía a Francisco Delgado por título de venta que el rey hizo a su padre el capitán Gaspar Delgado. Tanto los alcaldes ordinarios como el alcalde mayor eran nombrados por el señor y ejercían la jurisdicción en su nombre. Suyas eran las penas de cámara (íbid., fols. 650653).

212 Esta villa, su merindad y jurisdicción tenían un corregidor puesto por el Condestable. No respondieron al mandamiento de Luxján (AGS-CC, 2764, fols. 228-230).

${ }^{213}$ Hay dos alcaldes ordinarios nombrados por el concejo en nombre del tey que conocían a prevención con el administrador y su alcalde mayor, nombrados por el rey, todas las causas civiles y criminales de cualquiez clase que fueran y se dieran en la vilta y su tierra. Las penas de cámara y otros derechos iban a parar por merced real al hospital y casa real que había en la villa (ibid., fols. 359-363).

214 Los alcaldes ordinarios, que eran nombrados por la villa a quien pertenecía la jurisdicción, conocian civil y criminalmente en la villa y en los lugares que se encontraban bajo su jurisdicción. De ella y ellos eran las penas de cámara; del Condestable las alcabalas y la posibilidad de realizar visitas y residencias (ibid., fols. 524-532).

${ }^{215} \mathrm{La}$ villa y sus lugares declaran que la jurisdicción les pertenece y que la ejercen mediante un alcalde ordinario que nombran anualmente. Para reafirmar esta idea, declaran que el Conde no pone alcalde mayor, ni mayordomo porque la jurisdicción era de la villa. Del conde eran, sin embargo, las penas de cámara. Del rey, las alcabalas y el servicio real (íbid., fol. $380-384 \mathrm{v}^{\circ}$ ).

216 Señorío catalogado por Moxó de antiguo. En 1596 su titular compró las alcabalas («La venta de alcabalas", págs. 523-524).

217 El duque además de nombrar a las justicias ordinarias, ponia un gobernador. Las penas de cámara eran suyas. El rey percibía el servicio real (AGS-CC, 2764, fols. 437-439v').

${ }^{218}$ Los dos alcaldes ordinarios los nombraba anualmente la villa (ibid., fols. $437-439 \mathrm{v}^{\circ}$ ).

Nispania, 1,IX/2, núm. 202 (1999) 493-531 
Yluña

Ynestrillas

Ynojosa

Ysar

Ytcro la Vega

Y\%carc

\section{Lista complementaria:}

Baños de Valdearados

Barahona

Cabezón de la Sierra

Castro de Peones

I-Iacinas

Pancorbo

Pinilla
Valle de Luena

Inestrillas

Hinojosa de la Sicrra

Isar

Itero de la Vega

Ezcaray
Scñorio L. ${ }^{219}$ C. Ilurtado de Mendoza 220
Baños de Baidearados

Barahona

Cabczón de la Sierra

Hacinas

Pancorbo

Espinilla
Behctría 221

Señorio l. ${ }^{222}$ Marquućs dc Villena

Señonio L 223 Antonio Manrique de Lara

Señorio E. 224 Rcy

Señorio L. ${ }^{225}$ Conde de Monterrcy

Scñorio L. ${ }^{226}$ Marqués del Infantado

${ }^{219}$ Su señor adquirió las alcabalas por venta realizada en 1588 (S. DF: Moxó, «La venta de alcabalas», pág. 521).

22() Era el titular en 1588 (ibidem).

221 La jurisdicción criminal era del Condestable de Castilla, sujeto a la jurisdicción de santo Domingo de Silos. La civil, del Condestable y de la villa de Coruña (del conde de Coruña) a prevención (AGS-CC, 2764, fols. 335-337).

222 Exa ésta una pequeña villa perteneciente al condado de Santiesteban. Como sabemos (vid. not de Ayllón) el condado pertenecía al Marqués de Villena el cual nombraba, para todo él, un gobernador que residía en la villa de Ayllón y un alcalde mayor. Los alcaldes ordinarios de la villa los nombraba también el matqués. De él eran todas las imposiciones a excepción del servicio real (ibid., fols. 222-223).

223 Se trata de un lugar pequeño y de pocos vecinos, cuyo concejo nombraba anualmente dos alcaldes ordinarios que habian de ser confirmados por el señor o por su alcalde mayor que residia en la villa de San Leonardo. Las tercias y las alcabalas de Cabezón de la Sierra eran del Condestable de Castilla. Las penas de cámara que antes eran de Antonio Manrique de Lata, ahora pertenecían al rey por quien está de presente tomada la posesión) (ibid., fols. 325327 ).

224 Aunque la villa era del rey, como lo exan también sus alcabalas y el servicio real, la jurisdicción pertenecía al Monasterio de las Huelgas. De ahí que fuexa la abadesa de ese monasterio la que confirmaba a los alcaldes ordinarios -primera instancia civil y criminal- nombrados por la villa y la que nombraba al alcalde mayor -primera y segunda instancia civil y criminal-. Este panorama se complica si añadimos que los alcaldes ordinarios de Briviesca podían conocer la primera instancia a prevención (ibid. fols. $252-254 \mathrm{v}^{\circ}$ ).

${ }_{22} \mathrm{La}$ villa pertenecía al conde de Monterrey desde tiempo inmemorial y uan oydo decir que es uno de los pueblos yncorporados a su mayorazgon. Los dos alcaldes ordinarios exan nombrados por el concejo y ejercían la jurisdicción civil y criminal, alta y baja. De sus sentencias, en grado de apelación, conocía el alcalde mayor nombrado por el conde. Del concejo eran las penas de camara (ibid., $322-324 \mathrm{v}^{\circ}$ ).

226 El marqués nombraba todas las justicias y recibia las alcabalas, penas de cámara y otros derechos a su señotio debidos. Se afirma que el rey no tenía ningún derecho en ella (ibid., fols. 248-251).

Hispania, LIX/2, núm. 202 (1999) 493-531 


\begin{tabular}{|c|c|c|c|}
\hline Reguera & Vigucra? & Señorio L. 227 & Conde de $A$ guilar \\
\hline Santoña y su puerto & Santona y su puerto & Rcalcugo & Rcy \\
\hline Villezmalo & & Señorío L. 228 & Juan de f Iuguarte \\
\hline
\end{tabular}

Cabecera I.ugares bajo su juriscicción

Aguilar del Rio Alhama:

Almazán:

Arlanzón:

Ayllón y Condado de Santicsteban: Bañares:

Berlanga del Duero:

Cabezón de la Sal y su valle: Cabuérniga, valle de: Calatañazor:

Caracena:

Castildelgado (Villapún):

Castilnovo:

Castroscrna de Arriba:

Ccrezo:

Cieza y su valle:

Comillas:

Coruña:

Fresno de Cantespino:

Fuentepinilla:
Navajún y Valdemadcra.

40 lugares (s.e.).

Urrez, Zalduendo, Galaide, Cascra de Portilla y Hcrramel.

38 lugares (s.c.).

Se habla de la villa y su condado (sc.).

Hortezuela, liuente el l'utereo, Rebollar, Cirucla, Ias Casillas Caltojar, Bordecorex, La Riba de Escalote, Arenillas, La Cabrerica, Lumics, Alaló, Abanco, Pcones, Morales, Aguilera, Bayugas de Arriba, Bayugas de Abajo y la mitad de Brias.

Ibio, Mazcuerras, Pcricdo, Santibañez, Ontoria...

14 lugares: Villanueva, Bárcena Mayor, Viaña, Sclores, Rucnte... 16 lugares (s.e.), más Adehuela y su arrabal.

20021 lugares (s.c.).

Ibrilios.

Valdesanz, Villafranca, 'Oorrecilla y La Nava.

Castroserna de Abajo y Ventosilla.

Quintanilla de San Gareia, San Pedro del Monte, Redecilla del Campo, Sotillo, Quintanilla de las Ducĩas, Tormantos, Fonzalcchc, Arce, San Millán de Yécora

Heternia, Pradilla, San Vicente del Valle, Espinosa del Monte, San Clcmente, Ezquerra, Villagalijo, Santa Olclla, Pradoluengo, Valmala, Alarcia, Uzquiza, Villamorico, Santovenia, Agés, San Juan de Ortcga, Quintanilla de San Juan, Villa Sarsilla,

Villnescusa de la Solana, Pedrayta, Santa María del Invierno, Alcocero, Cilbacardel, Villamondar, Villalvos, Quintanaloranco, Loranquillo 230 .

Villayuso y Villasuso.

Ruiloba, Cobreces, 'Toñanes, Cigüenza, Novales, Rudagüera,

Udias y Ruiseñada.

2 aldeas y un arrabal (s.c.).

Aldeanucva, Sequera, Castilterra, Riasvelas, Cascajares, lajares, Cincovillas y Gomenaharros.

Osona, La Seca, La Ventosa, Fuentelárbol, 'Forreandaluz, Valderrodilla, Tajueco, Andaluz, Centanera, Valderrueda.

\footnotetext{
227 Los alcaldes ordinarios nombrados por la villa conocían la primera instancia acumulativamente y a prevención, mientras que la apelación la conocía el alcalde mayor puesto por el conde. De él eran las alcabalas y las penas de cámara (ibid., fols. 658-660).

228 Tenía un alcalde ordinario nombrado por el concejo y un alcalde mayor puesto por el señor que conocía todos los pleitos. Las penas de cámara eran del señor, mientras que el rey percibia tercias, alcabalas y servicio real (ibid., fols. $582-583 \mathrm{v}^{\circ}$ ).

229 Sujetos a su jurisdicción en mataria civil y criminal.

230 Sujetos a su jurisdicción sólo en materia civil.
}

Hizpania, LIX/2, núm. 202 (1999) 493-531 
l'ucntidueña (y su ticrra):

Gama y su valle:

Gormaz:

Waza:

Jubera:

Junta de Juarros y la Mata:

I a Pucbla de Arganzón:

Maderuclo:

Miedes de Aticnza:

Monteagudo:

Muño:

Nieva (de Camcros):

Ojacastro:

Ontoria del Pinar:

Osma:

Espinilla: (rcv).

Qucl:

Reguera:

Riaza de la Sierra:

Rucsga y su vallc:

San Román:

Santa Cruz del Valle:

Santa Gadea de Campoo, alfor de:

Santibañc\% de Valdesgueva:

Santillana, abadía de:

Santoña y su puerto:

Scrón:
Jos Valles, Fiuente el Olmo, Torrecilla, Fuente Pincs, Cozuclos, Vegafría, l'uentesauco, Mcmbibre, Ndeasona, Calabazas, Ccbibar, Sagramena, Pecharroman (?), Balticndas, I'ucntesoto, I'cjares, Torredrada, Castro, Cobos y San Migucl.

Reuedo, Villacibio, Val y luente 'loma.

Quintanillas (de Gormaz), l'ucntetorres, Vildé, Villanucva (de Gorma:), Recuerda, Galapagares, Nograles, Mosajeros (?), Prodamio (?) y la mitad del lugar de Brias.

8 lugarcs: Castrillo, l'uentecén, Adrada, l-Iortangas, Valdezate, luentemolinos...

9 lugares (s.c.).

Quintanilla de Ausín, Modúbar, Ibeas de Juarros, Santa Cruz de Juarros, San $\Lambda$ drián de Juarros, Cueva de Juarros, Cubillo de la Casa, Cubillo del Campo, Salgücro de Juarros, Modübar de San Cebrián, San Millán de Juarros, San Andrés, Revillarruz, Mozoncillo, Cuzcurrita, Cuevas, Bricva de Juarros, Vilamicl de la Sicrá y Cubil de la Cesa (ésta a prevención con la villa y tierra de Villanucva (aldea).

13 aldcas (s.c.)

Campisábalos, Condemios de Abajo, Condemios de Arriba,

Albendiego, Somolinos, Xador, Torrubio.

Chereoles y Jucntelmonte.

Quintanila de Somuño, Villaverde del Montc, Arroyo y l'clilla ${ }^{231}$. Reverga, Zacl, Torrecilla del Monte, 'lornadijo, Cogollos,

Valdorros, Muntuenga, Villafuentes, Villagóm*\% Bascooncillos, Villanucva de Matamala, Villamicl, Cabiscucla, Cabia,

Las Quintanillas, Medinilla, Villagutéerez, Vilvicstrc, 'Iamarón, Villaldcmiro, Villanueva de las Carretas, Calada y

Torrepadicrnia 232

Montemediano y Las Llanas (aldeas).

8 o 10 lugares (son cascrios y cabañas situadas en el montc y ticrras «nsperas» y de poca vecindad).

Navas y Santa María de los Casconcs (aldeas).

9 lugares (s.e.).

Hoz, Vilar, Naveda, Serna, Abrada, Barrio, Argücso y Mazandro. 1 aldea.

Panzares (aldea), más un barrio.

Riofrio.

6 Concejos: Matienzo, Arredondo, Riva, Ogarrio, Valle

y Las Cuestas.

Cabejón, Badillas, Labcllaneda y Almirón.

Soto, Garganchón y Riocavado.

Santa Gadea, Quintanilla, Arija c I Jigón.

Cabañcs y Pinillos.

Ubianco, Orcōa, Suances, Cortiguera, IIinojedo, l'ucnte, Veguilla,

3 aldeas: Peraita, Margotedo y Ducso.

Torreluenga, Valtucria y Cañamaque.

231 Que son vasallos de la ciudad de Burgos.

232 Pertenecen a la Merindad de Candemuño y no son vasallos de la ciudad de Burgos.

Hïpania, LIX/2, nüm. 202 (1999) 493-531 
Soba, valie de:

Soncillo (valle de Valdevezama):

Sotopalacios:

Sucllacabras:

'Torremuña:

Val de San Viccute:

Valdelaguna, valle de:

Villafranca-Montes de Oca:

Villalba de Losa:

Villanueva de Camcros:
Conccjos: Lferada, San Juan de IIondón de Soba, Regules y San Martin.

Lugares: liresnedo, ] a Revilla, Santayana, Rozas, Incedo, San l'cdro, $\Lambda$ ja, Beguilia, Villar, Javín, Quintana, Cañcdo, Valcaba y Villaverdc.

San Viecnte de Villamezán, $\lambda$ rgomcdo, Castrillo, Riaño, Quintanacntello, Montejo, I.Icrbosa, Brizucla, Virtus, l'ontedé (1'ucntedey), Quintanabaldo y Somabrian.

28 lugares.

2 lugares (pequeĩos, no suman más de 12 vecinos), (sc.)

Aldcas: Larrilla, L.ardigücla y l.adradilla.

l'radoluengo, Santolalla, San Vicente, lispinosa del Monte, San Clemente, Villagali o, Valmala y Alarcia

Hucrta de Yuso, lilucrta de Suso, Barbadillo de Herreros, Bezares, Quintanilla, Villajimcno, 'lolbatios de Yuso y 'Tolbanos de Suso. Villanucslia ?, Lispinosa del Camino, Carrias, Vilalómes, Ocón, Monzoncillo, 'Tirrientes, Cerratón, A hedillo, Villamudria, Rábanos y Puras.

Mijala, Zaballa Murita, Barriga, Villación Billota, Lastra y l'ča. Aldeas: Aldcanucva, Collan, Oyo, Marta y Zaballe. 